\title{
DINÁMICA ESPACIAL Y TEMPORAL DE LAS OCUPACIONES PREHISPÁNICAS EN LA CUENCA HIDROGRÁFICA DEL RÍO LIMARÍ (30 LAT. S.)
}

\author{
SPATIAL AND TEMPORAL TRENDS IN HUMAN PREHISPANIC OCCUPATION \\ IN THE LIMARÍ RIVER BASIN $\left(30^{\circ} \mathrm{S}\right)$
}

\author{
Andrés Troncoso ${ }^{1}$, Francisco Vergara ${ }^{2}$ Daniel Pavlovic ${ }^{1}$, Paola González ${ }^{2}$, \\ Mariela Pino ${ }^{2}$, Pablo Larach ${ }^{2}$, Antonia Escudero², Natalia La Mura², \\ Francisca Moya ${ }^{2}$, Isidora Pérez ${ }^{2}$, Renata Gutiérrez², Daniel Pascual ${ }^{2}$, \\ Carolina Belmar ${ }^{2}$, Mara Basile ${ }^{3}$, Patricio López ${ }^{1,4}$, \\ Cristian Dávila², María José Vásquez y Paula Urzúa ${ }^{2}$
}

\begin{abstract}
Este trabajo discute la secuencia de desarrollo histórico prehispánico en el Norte Semiárido de Chile a partir del estudio de las dinámicas espaciales y temporales de las ocupaciones humanas en la cuenca hidrográfica del río Limarí. A partir del estudio de asentamientos, materiales depositados en colecciones y arte rupestre se observa una secuencia de transformaciones y desarrollo desde el Arcaico Temprano hasta el período Incaico que diverge de lo tradicionalmente planteado para la región, reconociéndose ritmos de cambios sociales diferenciales dentro de la misma zona, especialmente en relación con la tradicional asociación entre incorporación de cerámica y la constitución de un modo de vida agrícola. La incorporación del arte rupestre permite articular sus características espaciales y representacionales con procesos más amplios, discutiéndose las relaciones establecidas entre dinámicas y cambios sociales con los flujos de información que producen las representaciones rupestres y sus respectivas audiencias.
\end{abstract}

Palabras claves: norte semiárido, cuenca hidrográfica del río Limarí, secuencia histórica, patrón de asentamiento, arte rupestre.

This paper discusses the pre-Hispanic sequence of historical development in the semiarid north of Chile through the study of spatial and temporal dynamics of human occupation in the Limari valley. Based on the study of settlements, museum collections and rock art, a sequence of transformations and development between the Early Archaic and Inca Period is observed that differs from what is traditionally known of the area. In this time frame, social changes such as the adoption of pottery and the constitution of an agrarian way of life, occur at different paces in both time and space within the same Limari valley. We discuss spatial and representational characteristics of rock art in relation to pre-hispanic social processes, emphasizing the links between audiences, flows of information and the dynamics of social life.

Key words: Semiarid North, Limarí valley, historic sequence, settlement pattern, rock art.

Las secuencias histórico-culturales son la base para pensar e interpretar los procesos sociales pasados, por lo que corresponden a piezas claves en cualquier investigación arqueológica. Aunque las primeras secuencias para diferentes regiones de los Andes se remontan a inicios del siglo XX, ellas fueron refinadas y ajustadas en las décadas de
1960 y 1970, siguiendo las propuestas de Willey y Phillips (1958). El Norte Semiárido de Chile no es la excepción a esta situación. Por sobre los tempranos trabajos (p.ej., Latcham 1928, 1937), las investigaciones en los valles de Elqui y Limarí entre 1940-1970 sentaron las bases para la actual secuencia histórico-cultural de la región (p.ej.,

1 Departamento de Antropología, Facultad de Ciencias Sociales, Universidad de Chile, Santiago, Chile. atroncos@uchile.cl; daniel.pavlovic@gmail.com; patriciolopezmend@gmail.com

2 Proyecto FONDECYT 1110125. f.vergaramurua@gmail.com; paoglez@gmail.com; marielitapino@ gmail.com; pablolarach@gmail.com; antomorgana@gmail.com; amilay@gmail.com; franmoya.c@gmail.com; isidafe@gmail.com; cristiandavilac@gmail.com; renatags@gmail.com; danipascual79@gmail.com; carolina_belmar@hotmail.com; joselita.vf@gmail.com; purzuaj@gmail.com

3 CONICET. Museo Etnográfico J.B. Ambrosetti, Facultad de Filosofía y Letras, Universidad de Buenos Aires, Argentina. Proyecto Pict2012-0196 y 2012-0596. basilemara@gmail.com

4 Programa de Doctorado en Antropología, Instituto de Investigaciones Arqueológicas y Museo (IIAM), Universidad Católica del Norte, Le Paige 348, San Pedro de Atacama, Chile. patriciolopezmend@yahoo.es 
Ampuero y Rivera 1964; Cornely 1956; Montané y Niemeyer 1960). Las propuestas resultantes fueron coherentes con la arqueología de la época, marcada por escasos fondos, una investigación centrada en el estudio de sitios aislados y una primacía de la noción de tipología=cronología. La secuencia resultante entregó un marco para comprender e interpretar los procesos históricos (p.ej., Ampuero e Hidalgo 1975; Ampuero y Rivera 1972-73). Un especial reconocimiento se dio a la aparición de la cerámica, en tanto marcador de sedentarismo asociada a la aparición de los primeros animales y plantas domesticadas.

Aunque buena parte de esos postulados siguen vigentes en la interpretación del registro regional (Ampuero 2010), trabajos con nuevos enfoques teórico-metodológicos las han reevaluado y delineado importantes modificaciones (p.ej., Jackson y Méndez 2005; Méndez y Jackson 2008; Pavlovic 2004; Troncoso et al. 2004). Sin embargo, estas reformulaciones se han focalizado en el sector sur del Norte Semiárido (31-32 ${ }^{\circ}$ Lat. S, valles de Choapa y Combarbalá), espacio con trayectorias y ritmos de desarrollo históricos diferentes a los de Limarí y Elqui (29-30 Lat. S) (Méndez y Jackson 2006; Troncoso y Pavlovic 2013). Si bien para Elqui-Limarí un conjunto de nuevos trabajos han complejizado el panorama regional, estos se han centrado en épocas más tardías y en aspectos puntuales (p.ej., Cantarutti 2002; Stehberg 1995; Suárez et al. 1989).

Nuestro trabajo se orienta a discutir el desarrollo prehispánico en el área central del Norte Semiárido a partir del estudio regional del registro arqueológico de la cuenca hidrográfica del río Limarí. Una revisión de la literatura muestra que en este espacio se encuentra una buena parte de los sitios-tipos sobre los cuales se construyó la secuencia histórica cultural (p.ej., Valle El Encanto, San Pedro Viejo de Pichasca, La Turquía, Puerto Aldea, Estadio Fiscal de Ovalle), además de ser un área menos alterada que Elqui por las empresas vitivinícolas.

Se implementó un programa de trabajo basado en prospecciones sistemáticas, intervenciones estratigráficas, dataciones absolutas y revisión de colecciones. El análisis de los datos consideró que las relaciones establecidas entre los asentamientos y sus conjuntos de cultura material dan cuenta de dinámicas sociales y económicas específicas que despliegan las comunidades a lo largo del tiempo (Billman y Feinman 1999; Chang 1983). En tal sentido, los patrones de asentamiento son producto de prácticas específicas de utilización del espacio de distinta naturaleza e intensidad, las que generan distintas articulaciones entre sujetos, objetos y lugares a lo largo del tiempo, entregándole una temporalidad e historicidad a estos procesos y lugares (Criado 2012; Ingold 1993).

Los resultados obtenidos nos permiten reevaluar la secuencia histórica en la zona desde el Arcaico Temprano hasta el período Tardío, observando divergencias con los modelos clásicamente propuestos y afinando la cronología de estos procesos a partir de dataciones absolutas. La inclusión del arte rupestre dentro de esta discusión posibilita integrar esta materialidad en los procesos sociales, aspecto escasamente explorado en la región.

\section{El Área de Estudio y sus Antecedentes Arqueológicos}

La cuenca hidrográfica del río Limarí (CHRL en adelante) se ubica en los $30^{\circ}$ Lat. S., una región de transición entre el desierto de Atacama y los valles mediterráneos de Chile central (Figuras 1 y 2). Su cuenca la componen diversos cursos hidrológicos de alimentación nival y orientación Este-Oeste, destacando los ríos Hurtado, Rapel y Grande, que confluyen cerca de la ciudad de Ovalle para dar origen al río Limarí. La cuenca muestra dos grandes conformaciones. La primera es de tipo cordillerana asociada a valles fluviales estrechos, de orientación E-W y encajonados por estribaciones de la cordillera de los Andes; alcanzan alturas entre 3.000 y $5.000 \mathrm{msm}$. Drenan a estos valles quebradas tributarias con flujos de agua estacionario de régimen pluvioso-nival y que son corredores para acceder a valles aledaños (Figura $3 b$ ).

La segunda es de tipo costero y se caracteriza por un paisaje más abierto. Desaparecen los cajones cordilleranos para dar paso a mesetas costeras con espacios poco aptos para los cultivos, los que se desarrollan en terrazas fluviales asociadas al río Limarí o esteros menores. Las mesetas costeras están cortadas por quebradas menores que desembocan en la línea de costa (Figura 3a).

Estudios paleoambientales efectuados en la costa de Los Vilos sugieren momentos húmedos para la transición Pleistoceno-Holoceno, comenzando hacia los 9.400 cal. a.p. una etapa de aridización que llevará a un establecimiento de condiciones más húmedas hacia el 4.200 cal. a.p. (Maldonado 

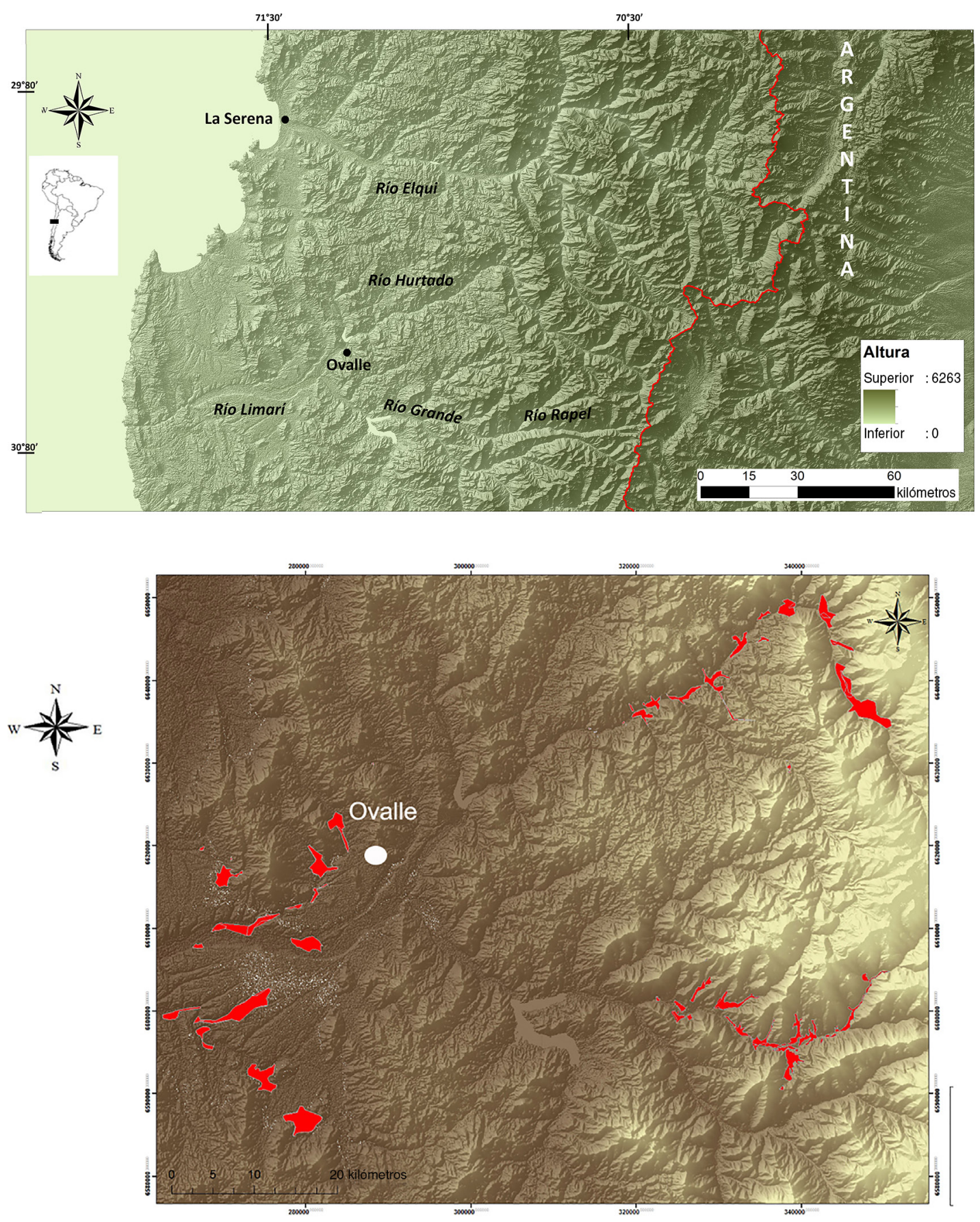

Figura 1. Mapa de la zona de estudio con demarcación de zonas prospectadas. Study zone. Survey areas are indicated. 


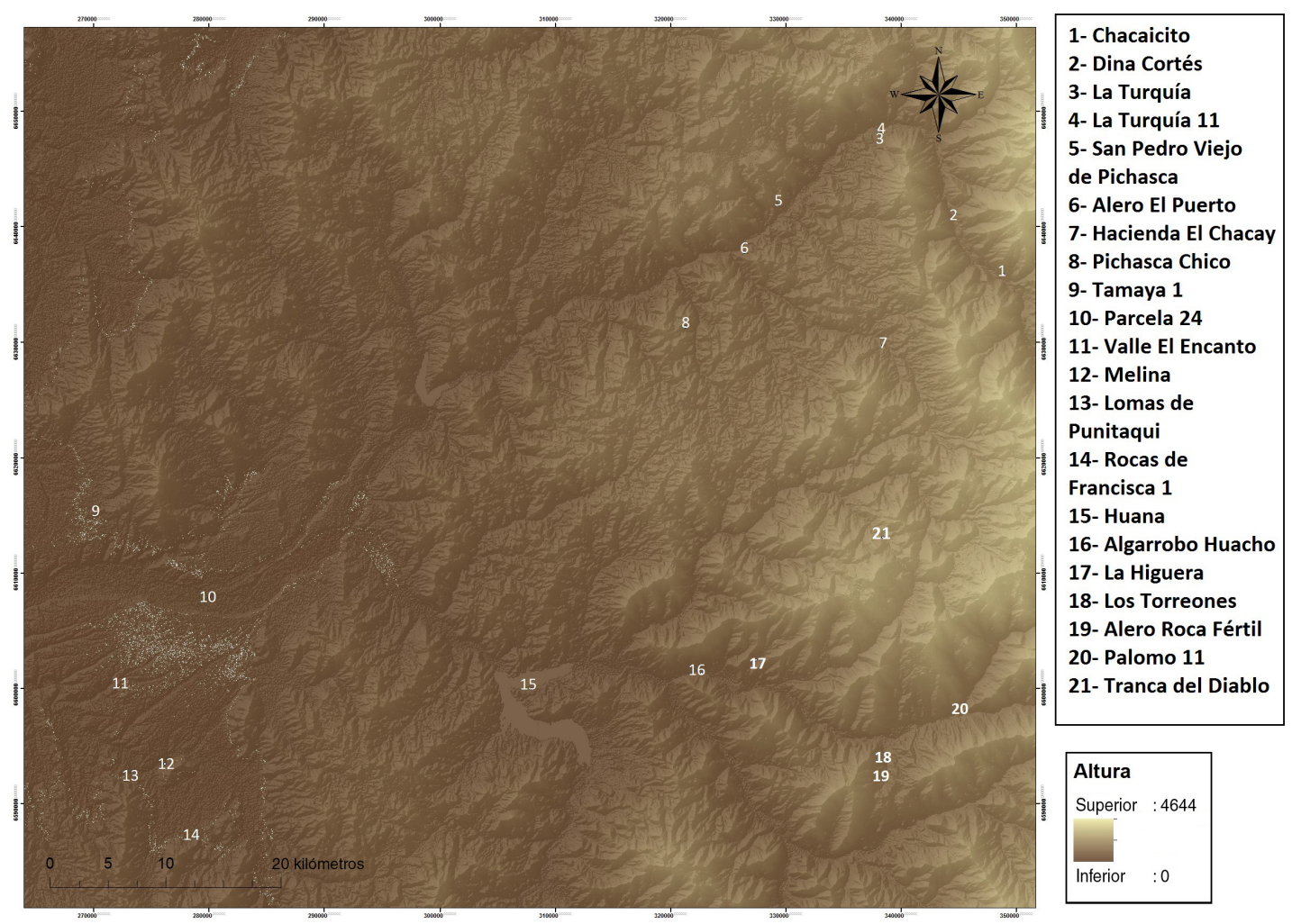

Figura 2. Mapa con indicación de los sitios nombrados en el texto. Map with sites mentioned in the text.
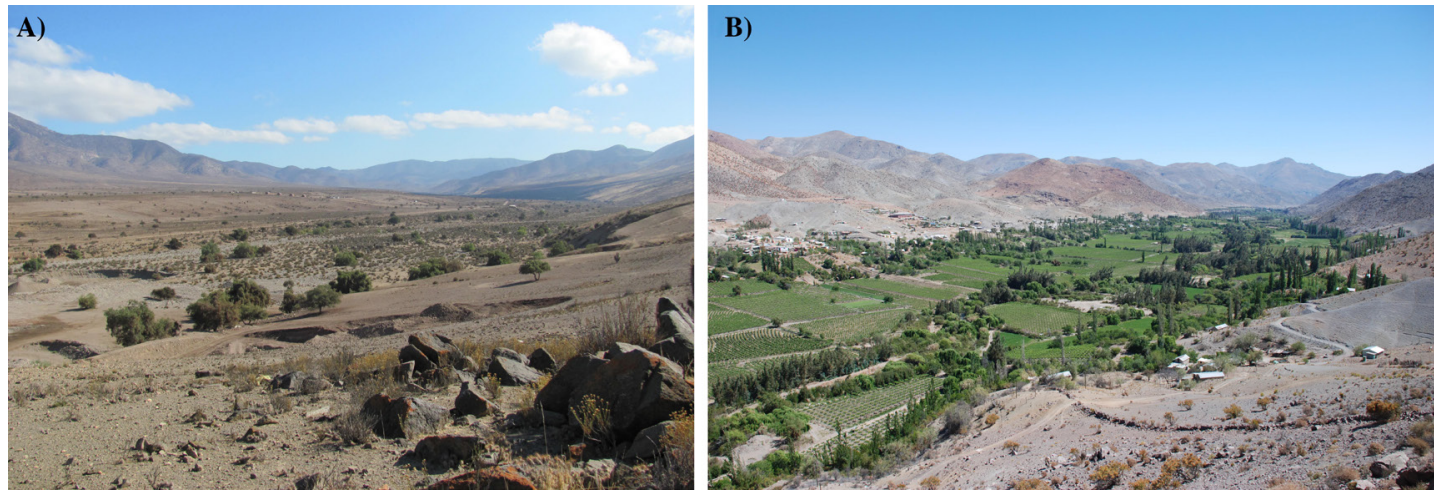

Figura 3. Vista de la cuenca hidrográfica del río Limarí: (a) curso inferior (sector La Placa), (b) curso superior (río Hurtado). Limarí river basin: (a) lower course (La Placa sector), (b) upper course (Hurtado river).

y Villagrán 2002, 2006; Villa y Villagrán 1997). No obstante algunas modificaciones, como una leve disminución de la humedad entre 3.000-2.200 cal. a.p., tales condiciones se mantendrán hasta la actualidad (Maldonado y Villagrán 2006).

Si bien la CHRL muestra un continuado derrotero de investigaciones desde inicios del siglo XX hasta la actualidad, los trabajos se concentraron entre 19401970. Las investigaciones con enfoques regionales no son recurrentes, destacando por ejemplo el trabajo de Stehberg (1995) sobre instalaciones Incaicas, o la investigación de Iribarren (1970) en el valle de Hurtado. Este último registra ocupaciones desde el período Arcaico Temprano hasta época Incaica 
y describe un conjunto de petroglifos que asocia al Período Alfarero Temprano (PAT), representado por el Complejo Cultural El Molle, y al Período Intermedio Tardío (PIT), representado por la Cultura Diaguita. La recurrencia de petroglifos ha llevado a la concurrencia de diferentes investigaciones centradas en definir su cronología (p.ej., Ampuero y Rivera 1971a; Castillo 1985; Iribarren 1949, 1953; Niemeyer y Ballereau 2004), proponiéndose en la actualidad una secuencia desde el Arcaico Tardío hasta el período Incaico (Troncoso et al. 2008).

Los asentamientos del período Arcaico se caracterizaron a partir de los sitios Cárcamo (Ampuero 1969), San Pedro Viejo de Pichasca (Ampuero y Rivera 1971b) y Valle El Encanto (p.ej., Ampuero y Rivera 1964, 1969). Las excavaciones de Iribarren $(1958,1970)$ en el cementerio La Turquía entregaron un contexto alfarero y metalúrgico que caracterizó la ergología cerámica del Complejo Cultural El Molle y entenderla como una sociedad sedentaria; no obstante, las propuestas del carácter tardío del sitio dentro del desarrollo Molle (Iribarren 1958, 1970), las que fueron rechazadas posteriormente (Ampuero y Rivera 1969). Las mismas excavaciones en Valle El Encanto y San Pedro Viejo permitieron recuperar contextos habitacionales de este grupo que, en contraposición a lo anterior, mostraban una continuidad en el uso del espacio con las poblaciones del Arcaico Tardío. En esta discusión, la introducción de la alfarería fue interpretada como producto de migración poblacional asociada a la aparición del sedentarismo (Ampuero 2010; Ampuero e Hidalgo 1975; Niemeyer et al. 1989).

Excavaciones de cementerios (Iribarren 1970; Montané y Niemeyer 1960), asentamientos (Serani et al. 2004) y estudios de colecciones (Cantarutti y Solvervicens 2005; Suárez et al. 1989) han permitido caracterizar conjuntos materiales de la cultura Diaguita y obtener dataciones absolutas que no se condicen con las propuestas cronológicas clásicas, como ocurre en otros espacios del Norte Semiárido (p.ej., Troncoso 1999). Asimismo, el estudio de contextos funerarios, instalaciones arquitectónicas y el trazado del QhapaqÑam (Biskupovic 1999; Cantarutti 2002; Cantarutti y Mera 2004; Niemeyer 1969; Stehberg 1995) han posibilitado aproximarse a la ocupación incaica, caracterizada por la presencia de contextos con una importante ocupación del Tawantinsuyu mediada por poblaciones del Noroeste argentino (Cantarutti 2002; Troncoso y Pavlovic 2013).

\section{El registro arqueológico de la cuenca hidrográfica del río Limarí}

Nuestros trabajos se han efectuado a lo largo de toda la CHRL. En su sector inferior las labores se concentraron en el estero Punitaqui y alrededores de la ciudad de Ovalle. En el sector superior, en los ríos Hurtado y Rapel. En estos espacios hemos realizado prospecciones sistemáticas orientadas a la identificación y registro de asentamientos, arte rupestre y piedras tacitas; sondeos en sitios bajo reparos rocosos y a cielo abierto, excavaciones extensivas, revisión de colecciones cerámicas y un programa de dataciones absolutas de sitios excavados y colecciones de museos. El conjunto de información recuperada se sistematizó en bases de datos geoespaciales que permiten su caracterización y comparación a lo largo de la secuencia temporal.

Se prospectó $115 \mathrm{~km}^{2}\left(54 \mathrm{~km}^{2}\right.$ en PunitaquiOvalle, $35 \mathrm{~km}^{2}$ en Hurtado y $26 \mathrm{~km}^{2}$ en Rapel) (Figura 2), cubriendo diferentes relieves y geoformas, abarcando terrazas fluviales, quebradas interiores, conos de deyección, laderas de cerro y mesetas costeras. Estos resultados, sumado a la intervención estratigráfica de 15 sitios arqueológicos, el relevamiento de 1.369 bloques de arte rupestre y 176 piedras tacitas, el estudio de adherencias de 24 de ellas, registro de 430 piezas alfareras de colecciones (211 PAT, 219 PIT) y la obtención de un set de dataciones absolutas constituyen el corpus básico desde donde elaboramos nuestra propuesta, las cuales fueron calibradas por el programa oxcal 4.2 y usando la curva ShCal13 (Hogg et al. 2013) (Tabla 1).

\section{Las primeras ocupaciones del área}

Las ocupaciones más tempranas registradas remiten al Holoceno Temprano, identificándose dos componentes: la tradición San Pedro Viejo de Pichasca asociada a puntas triangulares y el Complejo Cultural Huentelauquén-Industria tipo Cárcamo (sensu Méndez y Jackson 2008) asociado a puntas pedunculadas. Mientras la primera está representada por el sitio tipo, las segundas se habían reconocido en quebrada Minillas en Hurtado (Iribarren 1970), en hallazgos superficiales en Rapel (Iribarren 1975) y en Cárcamo en Río Grande (Ampuero 1969).

A la fecha hemos identificado solo dos nuevos contextos asociados con este momento: Pichasquita 


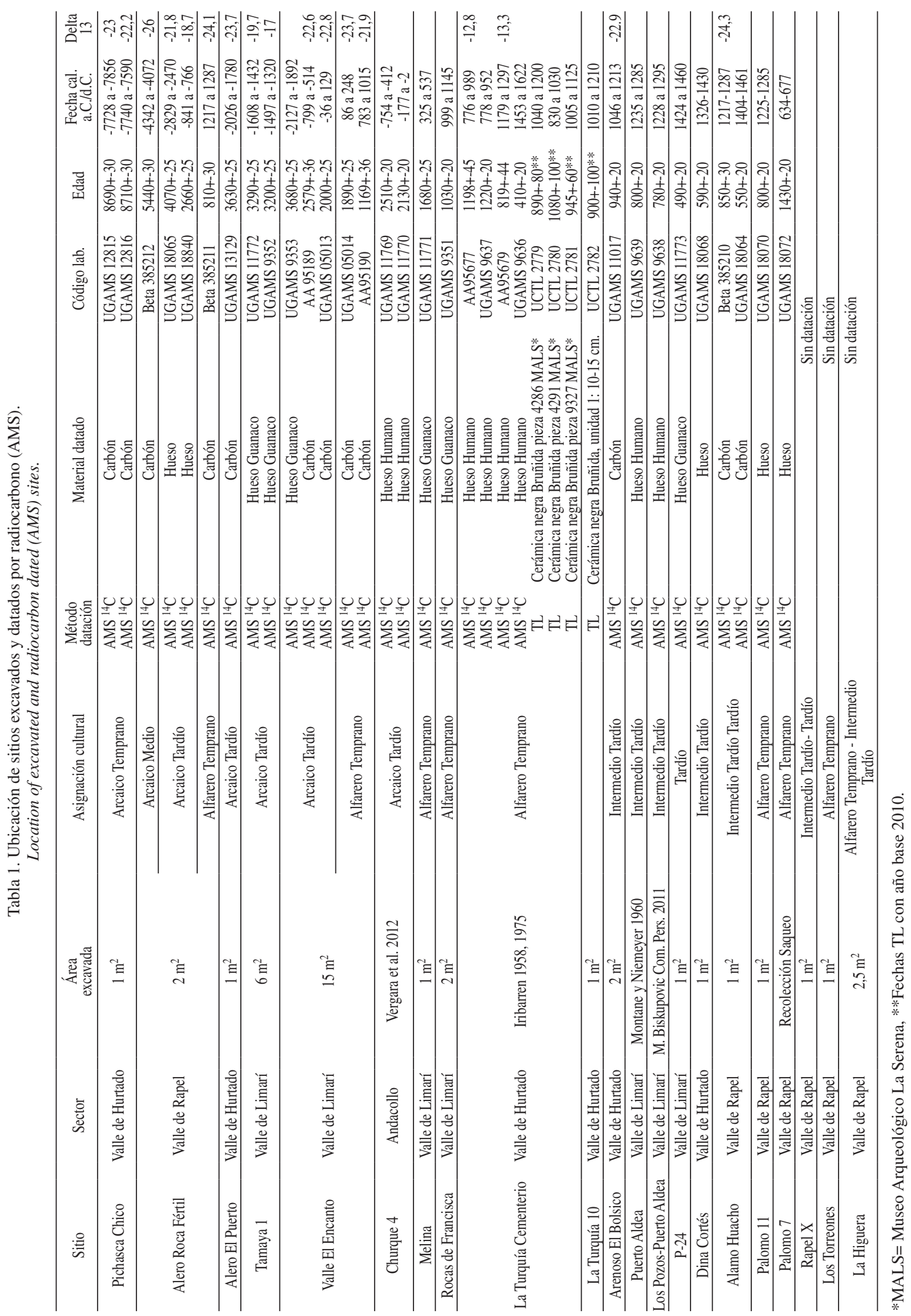


y Llanos de Punitaqui. El primero es un pequeño reparo rocoso emplazado en una quebrada afluente del río Hurtado y próximo a San Pedro Viejo. La excavación entregó una ocupación del Holoceno Temprano con un conjunto lítico $(n=1661)$, donde predominan piezas resultantes de retoque bifacial $(57,6 \%)$ y derivados de desbaste bifacial $(31,5 \%)$ en materias primas de granulometría fina, destacando la obsidiana $(0,1 \%)$, que es alóctona a la región. El conjunto instrumental presenta una punta pedunculada, un fragmento lateral de punta lanceolada, cepillo, raedera y raspadores (Figura 4a). Aunque predominan restos de guanaco, con un alto índice de exposición al fuego, unos pocos restos malacológicos indican contactos con espacios costeros. Correspondería a un campamento residencial transitorio que articularía con otros asentamientos no identificados en la localidad, uno de los cuales debería ser el vecino San Pedro Viejo.

Llanos de Punitaqui, ubicado en el sector inferior de la CHRL, es un extenso asentamiento emplazado en una terraza fluvial aledaña al estero Punitaqui donde se reconoce en superficie un fragmento de pedúnculo de punta de proyectil y una preforma de lito geométrico, junto con una industria caracterizada por abundantes desechos de talla lítica en materia prima silícea (Figuras 4b, 4c). Se ubica en una ruta natural de tránsito que permite conectar este sector con la costa vecina, específicamente con el área de El Teniente, donde hay ocupaciones contemporáneas (Weisner 1969).

Estas primeras ocupaciones muestran una clara, aunque puntual, presencia del Complejo Cultural Huentelauquén en la región (Tabla 2). En el sector inferior se asociarían, al menos, a rutas que conectan la costa con los vecinos valles costeros que son ricos en fuentes de materias primas líticas silíceas (p.ej., estero Punitaqui). En contraposición, en el interior las ocupaciones se concentrarían en quebradas secundarias idóneas para actividades de cacería (Jackson y Méndez 2005).

Los fechados de Pichasquita son posteriores a la primera ocupación de San Pedro Viejo, pero coherentes con una ocupación más tardía de tierras interiores por parte de las poblaciones Huentelauquén, enmarcándose en su fase II (11.0009.000 a.p.), que se relaciona con una ampliación en sus circuitos de movilidad y recursos explotados en respuesta a un proceso de aridización iniciado a finales del Holoceno Temprano (Jackson y Méndez 2005) (Tabla 1). La coexistencia de sitios bajo reparos rocosos como Pichasquita, quebrada Minilla y asentamientos a cielo abierto como La Fundición y CBL094-096 (Escudero 2012; Méndez y Jackson 2008) muestran la variabilidad y versatilidad de estas ocupaciones interiores. Un aspecto recurrente en varios de estos contextos interiores es la coexistencia de puntas triangulares con puntas pedunculadas, lo que se evidencia en el mismo sitio de San Pedro Viejo de Pichasca (Ale 2014), y que ha sido interpretado como producto de interacción social entre grupos de la tradición San Pedro Viejo y Huentelauquén (Jackson 1997). Desafortunadamente, la baja integridad estratigráfica de varios de estos sitios hace difícil evaluar esta hipótesis en mayor profundidad.

\section{Las comunidades móviles y los inicios de la variabilidad regional}

Como sucede en otras regiones, la señal arqueológica de las ocupaciones del Holoceno Medio es baja. Además de los niveles intermedios de San Pedro Viejo, asociado a puntas triangulares y datado entre los 7.700 y 4.400 cal. a.p. (Ampuero y Rivera 1971b), hemos identificado una ocupación en Alero Roca Fértil (Tabla 1). Corresponde a un abrigo rocoso emplazado en una quebrada secundaria. Su nivel de base muestra un conjunto lítico compuesto casi exclusivamente por derivados de talla más instrumentos informales. Su tecnología enfatiza el astillamiento bifacial (adelgazamiento y retoque), indicando manufactura local de piezas formales y su posterior traslado fuera del contexto. Los instrumentos bifaciales se manufacturan sobre rocas silíceas de buena calidad, las que ingresan altamente procesadas con escasa cobertura cortical. El registro zooarqueológico se compone básicamente de mamíferos indeterminados, con baja frecuencia de Lama guanicoe, Cricetidae, Chinchillidae y Octodon sp. Los restos de guanaco muestran baja diversidad de elementos óseos, restringiéndose a fragmentos de costillas, vértebra cervical y restos de molares inferiores, resultado de descartes en la fase final de procesamiento y consumo. La baja frecuencia de restos de guanaco sugiere, además, el traslado al sitio de unidades anatómicas muy segmentadas y con escasos huesos adosados, complementado con el consumo de faunas de menor tamaño (sobre todo roedores). Correspondería a un asentamiento logístico emplazado en una quebrada interior que le entrega conectividad intervalles y asociado a 

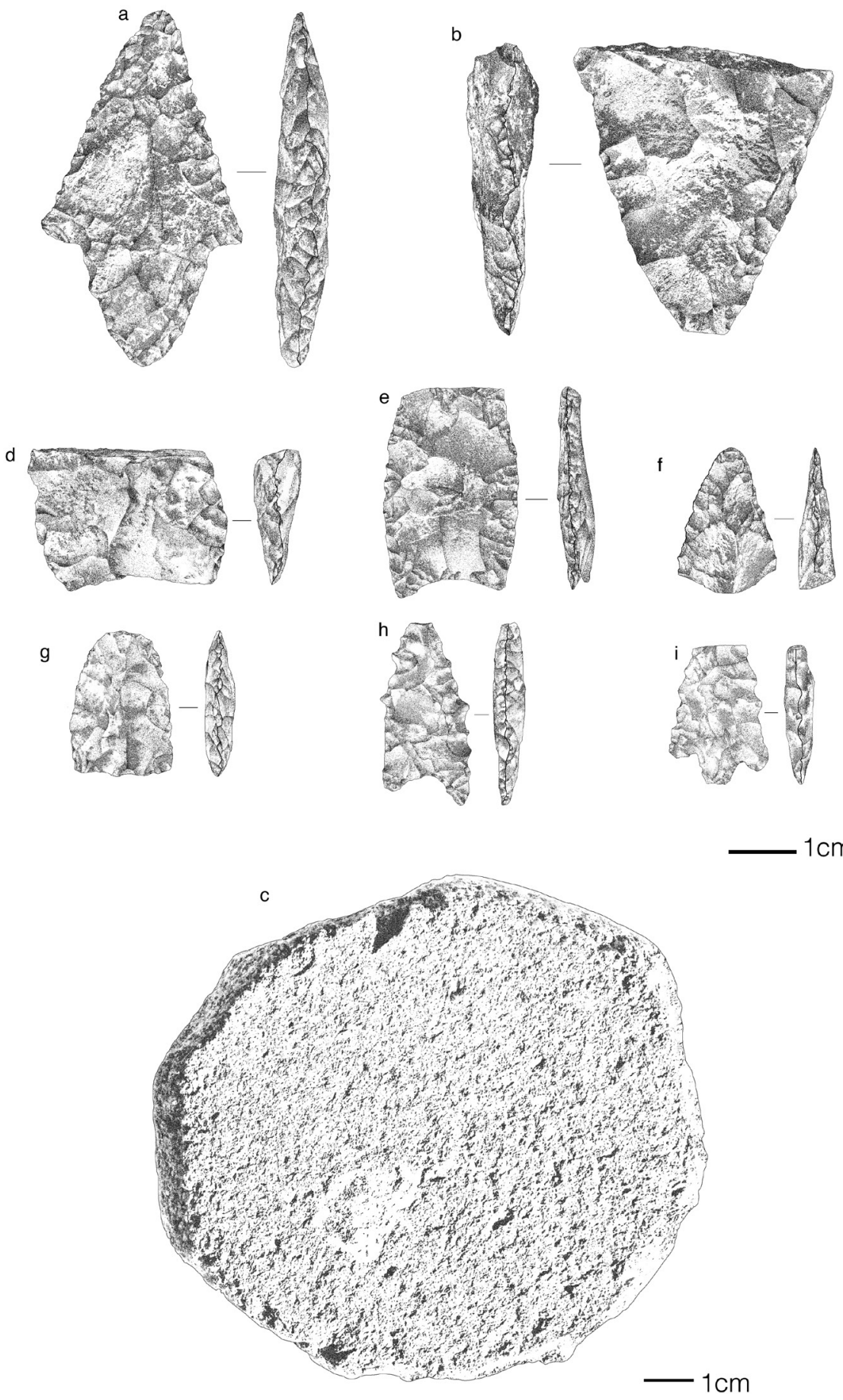

Figura 4. Material Lítico: (a) punta pedunculada (Pichasquita), (b) fragmento de pedúnculo, (c) lito geométrico (Llanos de Punitaqui), (d y e) fragmentos de punta de proyectil (Alero El Puerto), (f) punta de proyectil fragmentada (La Turquía 11), (g) fragmento de instrumento lítico (Melisa), (h) punta de proyectil fragmentada (Arenoso El Bolsico), (i) punta de proyectil fragmentada (Dina Cortés). Lithic material: (a) stemmed point (Pichasquita), (b) stem fragment of a projectil point, (c) cogged stone (Llanos de Punitaqui), ( $d$ and e) fragment of projectile point (Alero El Bolsico), $(f)$ fragment of projectil point (La Turquía 11), ( $g$ ) fragment of lithic instrument (Melisa), (h) fragment of projectil point (Arenoso El Bolsico), (i) fragment of projectile point (Dina Cortés). 
Tabla 2. Comparación de las pinturas rupestres en la cuenca inferior y superior de la hoya hidrográfica del río Limarí. Comparison of the rock art from the lower and upper courses of the Limarí river basin.

\begin{tabular}{|c|c|c|c|c|}
\hline \multicolumn{2}{|c|}{ Dimensión 1: atributos formales de los diseños no figurativos } & \multirow[t]{2}{*}{$\begin{array}{l}\text { Limarí Inferior } \\
\text { (Limarí) }\end{array}$} & \multirow[t]{2}{*}{$\begin{array}{l}\text { Limarí Superior } \\
\text { (Hurtado-Rapel) }\end{array}$} & \multirow[t]{2}{*}{ Total } \\
\hline Forma & Sintaxis & & & \\
\hline Línea & $\begin{array}{l}\text { Líneas aisladas } \\
\text { Diseños lineales con apéndices } \\
\text { Diseños lineales compuestos } \\
\text { Diseños lineales que forman áreas }\end{array}$ & $\begin{array}{r}20 \\
13 \\
22 \\
3\end{array}$ & $\begin{array}{r}19 \\
12 \\
16 \\
6 \\
\end{array}$ & $\begin{array}{r}39 \\
25 \\
38 \\
9 \\
\end{array}$ \\
\hline Círculo & $\begin{array}{l}\text { Sin decoración } \\
\text { Con decoración interna } \\
\text { Con apéndices } \\
\text { Con decoración interna y apéndices }\end{array}$ & $\begin{array}{r}5 \\
10 \\
2 \\
2 \\
\end{array}$ & $\begin{array}{l}3 \\
1 \\
1 \\
1\end{array}$ & $\begin{array}{r}8 \\
11 \\
3 \\
3 \\
\end{array}$ \\
\hline Cuadrado & $\begin{array}{l}\text { Con decoración interna } \\
\text { Con decoración interna y apéndices }\end{array}$ & $\begin{array}{l}3 \\
1 \\
\end{array}$ & $\begin{array}{l}1 \\
2\end{array}$ & $\begin{array}{l}4 \\
3 \\
\end{array}$ \\
\hline Rombos & Yuxtapuestos & 2 & 0 & 2 \\
\hline Trapecios & Sin decoración & 1 & 0 & 1 \\
\hline Puntos & Sin decoración & 3 & 1 & 4 \\
\hline Total & & 87 & 63 & 150 \\
\hline \multicolumn{5}{|c|}{ Dimensión 2: Tipos Decorativos } \\
\hline Forma & Tipología & & & \\
\hline Línea & $\begin{array}{l}\text { Cruz inscrita } \\
\text { Rectas en traslación } \\
\text { Meandro } \\
\end{array}$ & $\begin{array}{r}5 \\
6 \\
16 \\
\end{array}$ & $\begin{array}{l}0 \\
7 \\
2 \\
\end{array}$ & $\begin{array}{r}5 \\
13 \\
18 \\
\end{array}$ \\
\hline Círculo & $\begin{array}{l}\text { Círculos con apéndice } \\
\text { Círculos con decoración interna } \\
\text { Círculos con yuxtaposición } \\
\text { Círculos simples } \\
\end{array}$ & $\begin{array}{l}2 \\
9 \\
3 \\
4 \\
\end{array}$ & $\begin{array}{l}2 \\
1 \\
0 \\
1 \\
\end{array}$ & $\begin{array}{r}4 \\
10 \\
3 \\
5 \\
\end{array}$ \\
\hline $\begin{array}{l}\text { Cuadrado } \\
\text { Rombos } \\
\text { Trapecio }\end{array}$ & $\begin{array}{l}\text { Cuadrados con decoración interna } \\
\text { Rombos yuxtapuestos } \\
\text { Trapecio }\end{array}$ & $\begin{array}{l}4 \\
2 \\
1\end{array}$ & $\begin{array}{l}2 \\
0 \\
0\end{array}$ & $\begin{array}{l}6 \\
2 \\
1 \\
\end{array}$ \\
\hline Diseños indefinidos & & 35 & 48 & 83 \\
\hline Total & & 87 & 63 & 150 \\
\hline
\end{tabular}

Diferenciación estadísticamente significativa entre ambos espacios $\left(\mathrm{X}^{2}=29,791, \mathrm{df}=10, \mathrm{p}=0,0009\right.$. Estadístico exacto de Fisher $=$ 29,090; $\mathrm{p}<0,001$. Monte Carlo $\mathrm{p}=0,0004)$

Dimensión 3: Patrones de Simetría

Presencia/Ausencia

\begin{tabular}{llrrr}
\hline Ausencia & Ausencia & 33 & 47 & 80 \\
\hline \multirow{2}{*}{ Presencia } & Traslación & 35 & 14 & 49 \\
& Reflexión especular & 19 & 2 & 21 \\
\hline Total & & 87 & 63 & 150 \\
\hline
\end{tabular}

Diferenciación estadísticamente significativa entre ambos espacios $\left(\mathrm{X}^{2}=21,933 ; \mathrm{df}=2 ; \mathrm{p}=0,000001\right.$. Estadístico exacto de Fisher $=$ $22,686 \mathrm{p}<0,000$. Monte Carlo $\mathrm{p}=0,0001$ )

Dimensión 4: Color

\begin{tabular}{lrrr}
\hline Monocromo & 85 & 55 & 140 \\
\hline Bicromo & 2 & 6 & 8 \\
\hline Policromo & 0 & 2 & 2 \\
\hline Total & 87 & 63 & 150 \\
\hline
\end{tabular}

Diferenciación estadísticamente significativa entre ambos espacios $\left(X^{2}=6,762, g 12, p=0,034\right.$. Estadístico exacto de Fisher $=6,176$ $\mathrm{p}=0,028$. Monte Carlo $\mathrm{p}=0,0221$ )

Dimensión 5: Espacio

\begin{tabular}{|c|c|c|c|}
\hline Área prospectada & $54 \mathrm{~km}^{2}$ & $61 \mathrm{~km}^{2}$ & 115 \\
\hline Sitios de Arte Rupestre & 17 & 7 & 24 \\
\hline Bloques de Arte Rupestre & 36 & 7 & 43 \\
\hline Densidad Sitios por $\mathrm{Km}^{2}$ & 0,31 sitio $\mathrm{x} \mathrm{km}^{2}$ & 0,11 sitio $\mathrm{x} \mathrm{km}^{2}$ & \\
\hline N Bloques con Pinturas & 0,66 bloque $\mathrm{x} \mathrm{km}{ }^{2}$ & 0,13 bloque $\mathrm{x} \mathrm{km}{ }^{2}$ & \\
\hline N Pinturas & 2,38 pintura $\mathrm{x} \mathrm{km}^{2}$ & 3,65 pintura $\mathrm{x} \mathrm{km}{ }^{2}$ & \\
\hline
\end{tabular}


posibles fuentes de extracción lítica y prácticas de cacería de baja intensidad.

Las dataciones de ambos sitios concordarían con períodos de señales intensas de ocupación humana en la cordillera (Méndez et al 2015). Sus funcionalidades en tanto asentamiento residencial (San Pedro Viejo) y logístico (Alero Roca Fértil) indican un uso organizado de estos espacios cordilleranos. Esto se enmarcaría dentro de patrones de movilidad que articulan la costa y los valles interandinos de San Juan (Argentina) como estrategia para paliar las condiciones de aridez existentes (Jackson 2002).

Hacia el 4.000 a.p. los asentamientos son más visibles y recurrentes en la región (Tabla 1). Esta situación es coherente con lo que se conoce en la costa aledaña (transecto Guanaqueros-Punta Teatinos) y en espacios litorales cercanos (Los Vilos). En la costa aledaña a la CHRL esto se expresa en la conformación de grandes conchales-cementerios (Guanaqueros, La Herradura, Punta Teatinos y Museo del Desierto).

Hemos intervenido un total de cuatro sitios de este momento: valle El Encanto, Tamaya 1 (Limarí), alero El Puerto (Hurtado) y alero Roca Fértil (Rapel) (Tabla 1). Los dos primeros son sitios a cielo abierto ubicados en corredores naturales que permite el acceso al litoral a través de quebradas costeras. En estos sitios coexisten piedras tacitas, pinturas rupestres y depósitos estratigráficos abundantes en subproductos de talla de materias primas silíceas, especialmente desechos del desbaste marginal y bifacial de instrumentos; complementan estos conjuntos líticos puntas de proyectil triangulares y lanceoladas, raspadores, raederas y cuchillos (Figuras 4d, 4e). Los restos arqueofaunísticos son mayormente astillas carbonizadas de camélidos. Se recuperan también algunos fragmentos de ostión (Argopecten purpuratus) y erizo (Loxechinus albus) que dan cuenta de la obtención de recursos costeros.

Valle El Encanto y Tamaya 1 son campamentos residenciales a cielo abierto que aprovecharían su emplazamiento en espacios aptos para la recolección de frutos vegetales y su posterior procesamiento. Se insertarían en un régimen de movilidad que incluye la costa aledaña, reconociéndose asentamientos en la costa vecina con similares características (Schiappacasse y Niemeyer 1965-1966).

En contraposición, los dos sitios del interior son ocupaciones bajo reparos rocosos emplazados en quebradas secundarias, replicando el patrón de asentamiento de San Pedro Viejo. Alero El Puerto y Roca Fértil muestran un contexto con conjuntos líticos donde predominan los derivados de talla ( $>98 \%$ ), con una baja frecuencia de categorías artefactuales modificadas, destacando la presencia de puntas de proyectil triangulares y lanceoladas, raspadores y cuchillos (Figura $4 \mathrm{~d}, \mathrm{e}$ ). Las materias primas mayormente usadas son de tipo silíceas, contándose con algunos derivados de obsidiana en Roca Fértil. El registro zooarqueológico se compone de astillas carbonizadas y fragmentos de huesos largos de Lama guanicoe, aunque hay restos de otras especies en menor cantidad (Chinchillidae). Algunas piezas óseas han sido trabajadas para manufacturar instrumentos de extremo aguzado, las que se han reconocido en contextos contemporáneos y que se relacionan con el trabajo de materias primas blandas (Santander y López 2012) (Figura 5).

Estos sitios corresponderían a campamentos residenciales que continúan con las formas de uso del espacio previas, ocupando quebradas tributarias y reparos rocosos con amplias condiciones de visibilidad sobre el entorno circundante dentro de un sistema de movilidad residencial. La recurrencia de puntas de proyectil en estos sitios, las constantes prácticas de reavivados de filo y la ausencia de instrumental de molienda sugeriría una importancia de las actividades de caza por sobre las de recolección.

No obstante, las diferencias en el patrón de asentamiento, la industria lítica del Arcaico Tardío muestra una tecnología de orientación conservada con uso de materias primas de buena calidad, manufactura de bifaces o matrices óptimas para su transporte, tratamiento térmico de rocas y un alargamiento de la vida útil de las piezas a partir del reactivado de instrumentos.

La mayor visibilidad de los asentamientos en la región puede relacionarse con una mayor intensidad en la ocupación regional, posiblemente asociada a un aumento demográfico como ha sido planteado (Méndez y Jackson 2004; Quevedo 1998). Es en este momento cuando se inician los procesos de monumentalización del paisaje y de mayor formalización de los sistemas de información visual. Por una parte, aparecen las piedras tacitas (Schiappacasse y Niemeyer 1964) asociadas a sitios habitacionales. Por otra, las primeras manifestaciones de arte rupestre, correspondientes a pinturas, se emplazan también dentro de estos sitios. Su asociación con el Arcaico Tardío ha sido previamente sugerida (Ampuero 1966; Ampuero y Rivera 1971a; Iribarren 1973; Troncoso et al. 

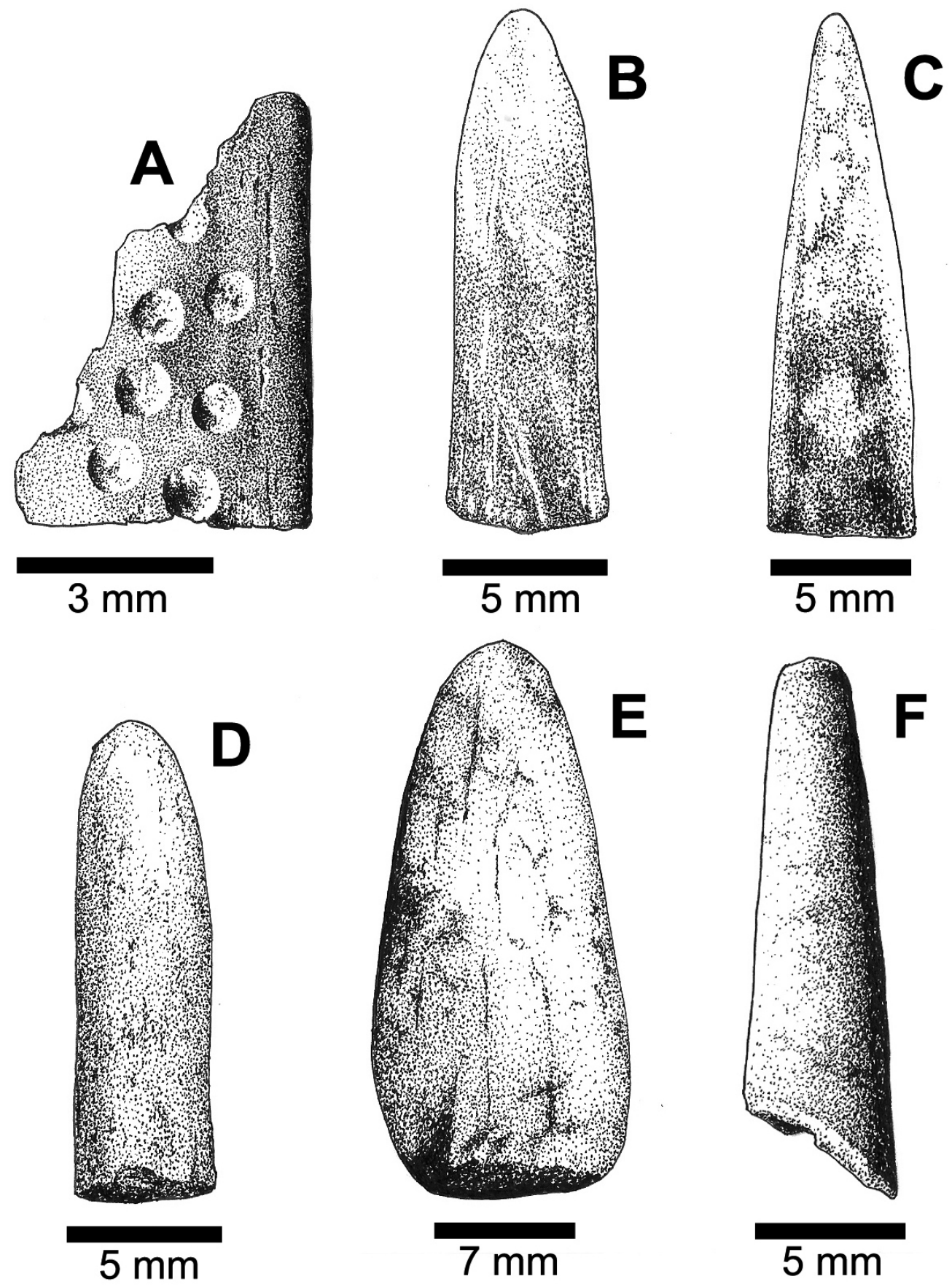

Figura 5. Instrumentos manufacturados sobre piezas óseas de animales, Arcaico Tardío: (a) Fragmento de hueso plano con punteados circulares, (b) Extremo distal de artefacto de extremo activo aguzado y sección transversal, (c) Extremo distal de artefacto de extremo aguzado y sección transversal oval-achatada, (d) Fragmento distal de artefacto de extremo aguzado y sección transversal circular (a-d: sitio Alero Roca Fértil), (e) Artefacto de extremo distal aguzado romo y sección transversal ovalada, (f) Extremo distal de posible punzón aguzado y sección circular (e-f: sitio Valle El Encanto) (Dibujos realizados por Elvira Latorre).

Late Archaic bone artifacts: (a) Flat bone fragment with circular dots, (b) distal extreme of an artifact with transversal section and sharpened active extreme, $(c)$ distal extreme of an artifact with transversal oval-flattened section and sharpened extreme, (d distal fragment of an artifact with transversal circular section and sharpened extreme, (a-d: site Alero Roca Fértil), (e) artifact with oval transversal section and sharpened blunt distal extreme, $(f)$ distal extreme of a probable sharpened awl with circular section (e-f: Valle El Encanto) (Drawings by Elvira Latorre). 
2008) y se refrenda por: (i) similitud de diseños y patrones de simetría (traslación horizontal y/o vertical) entre pinturas rupestres y otros diseños en bienes muebles del Arcaico Tardío (Figura 6), (ii) recurrente presencia de pigmentos en contextos Arcaico Tardío y en los depósitos de sitios habitacionales (p.ej., Tamaya 1, alero El Puerto, alero Roca Fértil) y (iii) coexistencia espacial entre pinturas rupestres y asentamientos de este tiempo. Otros soportes de lenguajes visuales son los instrumentos óseos (Figura 5a, 6c, 6d), sugiriendo una relevancia de estos sistemas de información visual en la constitución de las comunidades (Gamble 1982; Whallon 2011), en un contexto socioespacial caracterizado por una mayor presión sobre el espacio producto del uso más intensivo de la región (Méndez y Jackson 2004, 2006). Mientras el arte rupestre y las piedras tacitas anclan estos flujos de información en espacios específicos, los instrumentos óseos permiten su circulación.
Por sobre tal idea, Gamble (1982) y otros autores (p.ej., Mc Donald y Veth 2006) proponen que los lenguajes visuales serían recursos relevantes dentro de las dinámicas territoriales de este tipo de comunidades. Al compartir un mismo tipo de lenguaje se establecen sistemas de alianzas y redes entre diferentes bandas de cazadores recolectores. Esto generaría dos escenarios posibles. En contextos de territorialidad cerrada los sistemas visuales serían fragmentados y heterogéneos por la presencia de diferentes unidades sociales que se excluyen desde sus sistemas de información; en contraposición, en contextos de territorialidad abierta se daría un compartir de lenguajes visuales a amplia escala para fortalecer las alianzas y relaciones entre diferentes bandas.

Aunque las pinturas de la región son un corpus homogéneo que remite a similares principios de construcción, se observan variaciones entre la cuenca inferior y superior (Moya 2015). Estas se expresan
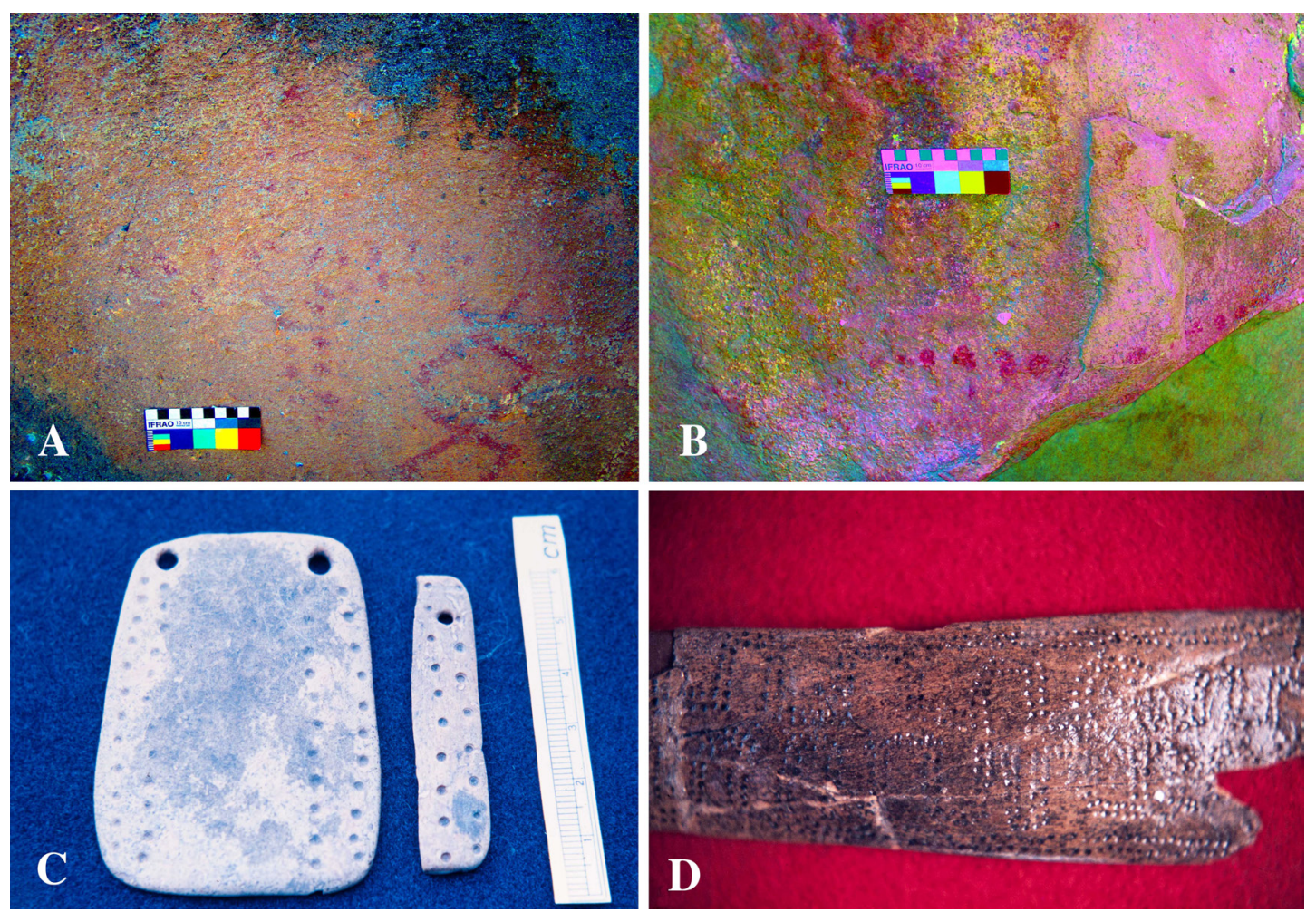

Figura 6. Sistemas visuales del Arcaico Tardío, pinturas trabajadas por D-Stretch: (a) La Placa 1, (b) Covacha Pintada; (c y d) instrumentos óseos Punta Teatinos (fotografías H. Niemeyer depositadas en el archivo Hans Niemeyer del Museo Nacional de Historia Natural).

Late Archaic visual systems, paintings digitally enhanced by D-Stretch: (a) La Placa 1, (b) Covacha Pintada, (c and d) bone instruments from Punta Teatinos (photographies by $\mathrm{H}$. Niemeyer, housed in the Archivo Hans Niemeyer at the Museo Nacional de Historia Natural). 
en el uso diferencial de algunos diseños, los patrones de simetría y los colores utilizados en cada uno de los sectores. Más aún, las combinaciones de tipos de diseño por bloque son excluyentes a cada zona y la recurrencia de las pinturas es significativamente mayor en la cuenca inferior que en la superior (Tabla 2; Moya 2015; Troncoso et al. 2014a). Todo esto indica que nos encontraríamos ante un sistema de territorialidad cerrada que segrega la cuenca inferior de la superior en Limarí, lo que se refrenda al observar que el patrón de asentamiento como las estructuras de los sitios diverge en ambos espacios. Mientras en la cuenca inferior hay una recurrencia de ocupaciones habitacionales a cielo abierto, piedras tacitas y pinturas rupestres; en la cuenca superior los sitios son reparos rocosos, sin piedras tacitas y con una menor densidad espacial de pinturas (Moya et al. 2014; Moya 2015). De hecho, y como indica Schiappacasse y Niemeyer (1964, 1965-66), los contextos de tierras inferiores darían cuenta de una mayor importancia de los recursos vegetales en la vida económica como lo atestigua el aumento del instrumental de molienda; en contraposición, los del interior mantendrían una orientación más cazadora (Ampuero y Rivera 1971b).

Estos mismos datos sugieren que el proceso de reclamación espacial sería más intenso en la costa desplegándose una mayor monumentalización del paisaje y un mayor flujo de información visual entre unidades sociales, como ocurre en la zona meridional del Semiárido (Méndez y Jackson 2006). La aparición de extensos conchales funerarios (p.ej., Punta Teatinos) se relacionaría con este tipo de procesos, sugiriendo unidades de agregación social a una escala previamente no reconocida en el registro regional. Evidencias bioantropológicas de violencia en estos contextos han sido interpretadas en relación con estos procesos socioespaciales de reclamación (Castelleti et al. 2012; Quevedo 1998). Lamentablemente el conjunto de dataciones no permite clarificar aún la dinámica temporal de este proceso en el Arcaico Tardío.

Aunque tradicionalmente se propuso que la aparición de la alfarería implicaba la consolidación de una vida aldeana y pastoril en el Norte Semiárido (Ampuero 2010; Ampuero e Hidalgo 1975; Niemeyer et al. 1989), estudios más recientes han puesto en tela de juicio este supuesto (p.ej., Méndez et al. 2009; Pavlovic 2004). Nuestros trabajos indican que la aparición de la cerámica no marcaría un quiebre en las dinámicas de ocupación y modo de vida, aunque sí se observan transformaciones. La cerámica es escasa en los primeros contextos alfareros (Figura 7a-d). Corresponden mayormente a vasijas restringidas, monocromas alisadas, de pequeño tamaño, con pastas compactas que le brindan resistencia mecánica, características idóneas para su uso en un modo de vida móvil, situación reconocida en otros espacios del Semiárido (p.ej., Méndez et al. 2009).

Cronológicamente, las dataciones más tempranas de ocupaciones con cerámica las tenemos en la cuenca inferior del Limarí, enmarcándose hacia inicios de la era cristiana (Tabla 1). Esta fecha es anterior a lo planteado previamente (Ampuero 1971). Dataciones en otros sitios, como Melina y Churque 4 (Vergara et al. 2012), muestran una clara presencia de alfarería hacia el 300 d.C.

Estos asentamientos se caracterizan por usar espacios similares a los ocupados previamente. Sitios como valle El Encanto, Tamaya 1, San Pedro Viejo de Pichasca, alero Roca Fértil y Churque 4 en Andacollo (Vergara et al. 2012) muestran continuidad estratigráfica entre ambas ocupaciones. Mientras en la cuenca inferior esto se expresa en sitios a cielo abierto en pequeñas terrazas aledañas a cursos de agua menores, en el interior son aleros dispuestos en quebradas tributarias de valles. Como hemos expuesto en otro trabajo (Troncoso et al. 2008), y lo han sugerido otros autores (Ampuero y Rivera 1971a; Iribarren 1973), se mantiene la producción de pinturas como se desprende de la presencia de sitios monocomponentes con cerámica y pinturas rupestres (Castillo 1985; Troncoso et al. 2008). Las piedras tacitas continúan durante este momento y aumenta su cantidad, como lo indica su recurrencia con ocupaciones PAT en la cuenca inferior y las dataciones obtenidas de depósitos aledaños que muestran presencia de instrumentos de molienda (Tabla 1 UGAMS 05014) (Pino 2012; Troncoso et al. 2015).

Esta industria lítica tiene una orientación más expeditiva que conservada aunque ambas estrategias coexisten. Se privilegia el uso de rocas locales, ígneas, de calidad regular para la manufactura de instrumentos informales que se manufacturan profusamente. $\mathrm{La}$ industria curada está menos representada. Se observa una prevalencia de derivados asociados a la talla marginal (60\%), de instrumentos informales en detrimento del adelgazamiento y retoque bifacial (alrededor del 10\%), coherentemente con los escasos instrumentos formales de astillamiento bifacial. El instrumental curado corresponde 

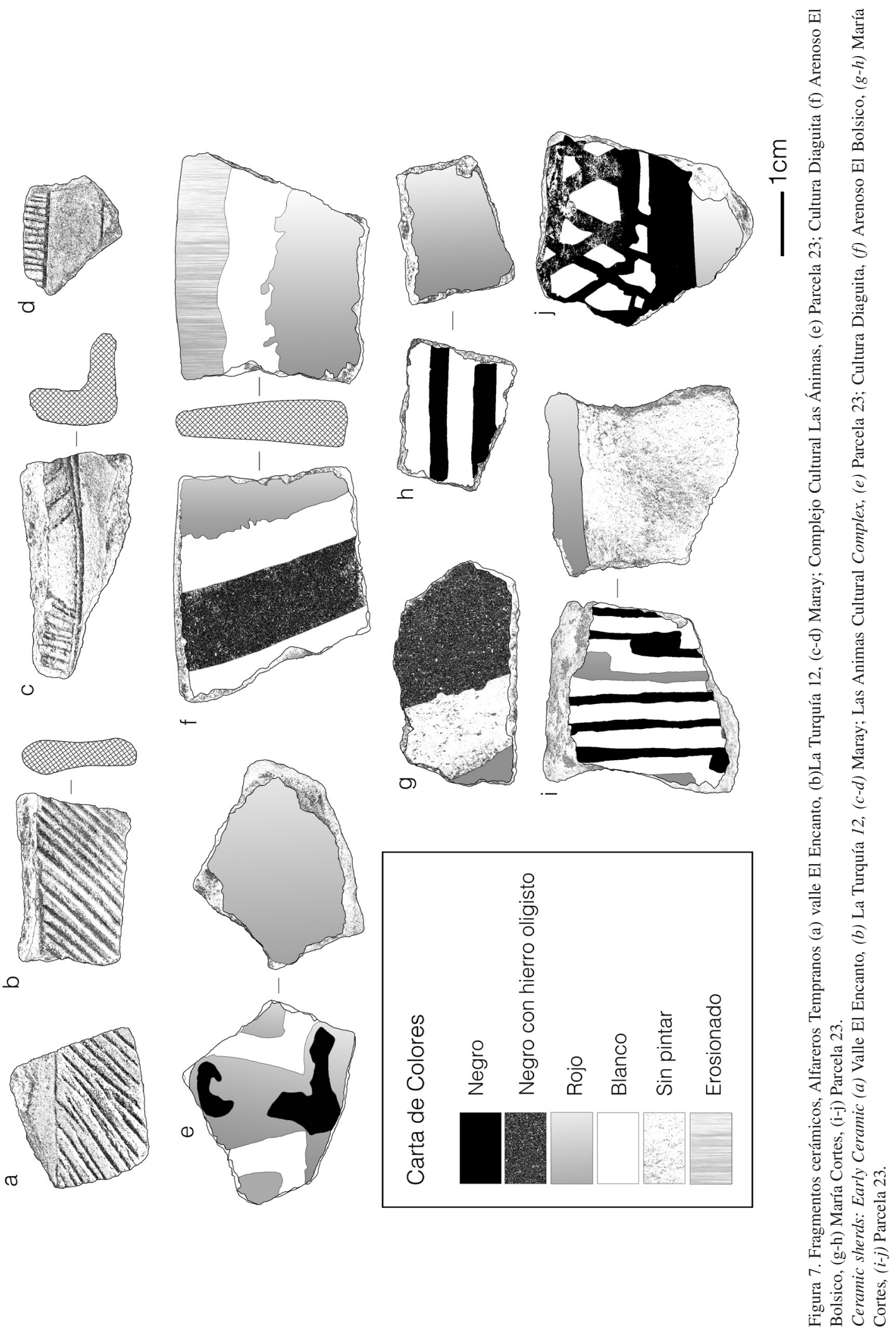
casi exclusivamente a puntas de proyectil. Estas mantienen una morfología similar a las del Arcaico Tardío, son manufacturadas sobre rocas silíceas de buena calidad, pero de dimensiones más reducidas y secciones más delgadas producto de su elaboración a base de lascas (Figura 4f-g). Las actividades de reciclaje son menores debido, entre otras cosas, a los tamaños menores de estas piezas que disminuyen su vida útil mediante el reactivado y reducen las posibilidades de reutilización o retomado. Los conjuntos zooarqueológicos muestran una menor variedad de recursos explotados y remiten básicamente a camélidos, como ocurre en otros contextos PAT del Semiárido.

La continuidad en los usos del espacio, estructuración de los sitios y contextos materiales de los asentamientos, sugieren la continuación de un modo de vida basado en la movilidad residencial. Los cambios en las industrias líticas y mayor cantidad de asentamientos sugieren una reducción en los circuitos de movilidad. La intensificación en producción de piedras tacitas sería coherente con el proceso anterior (Troncoso et al. 2015). Es relevante mencionar que en la cuenca inferior este proceso va acompañado de la desaparición de los grandes conchales funerarios del Arcaico Tardío, reemplazados por enterratorios aislados en los asentamientos. Las dos últimas situaciones sumada a las propuestas esbozadas acerca de un escaso registro de ocupaciones PAT en la costa (Niemeyer et al. 1989) sugieren que a pesar de la continuidad con el Arcaico Tardío las primeras ocupaciones con cerámica serían parte de un proceso de reorientación económica que lleva a utilizar más recurrentemente los espacios del interior a la luz de una mayor intensidad en el uso de vegetales. Aunque los estudios de macrorrestos por flotación de sedimentos de los sitios valle El Encanto y Tamaya 1 no han entregado restos de cultígenos, la extracción de almidones desde piedras tacitas asociados a este momento ha evidenciado microfósiles asignables a Propopis sp., Zea mays y Cucurbitaceae (Troncoso et al. 2015).

Un cambio significativo en estos contextos se da post-500 d.C. y se asocia a la conformación de los registros más típicamente Molle. Aparecen los cementerios con ruedos de piedra emplazados sobre cumbres de cerros en la parte cordillerana de Limarí, los que junto con presentar condiciones de visibilidad excepcionales que los vuelven hitos relevantes dentro del paisaje local, materializan una importante inversión de trabajo en su construcción al ser elaborados con rocas trasladadas desde las cajas de los ríos adyacentes. Mientras en Hurtado, Iribarren $(1958,1970)$ describe seis de estos cementerios para el sector de La Turquía (Figura 8a-b), en Rapel hemos identificado otros cuatro, variando desde solo una tumba en ruedo hasta, al menos, 20 estructuras en Palomo 11, el grueso de ellas saqueadas. Estos cementerios tienen ricos contextos cerámicos y metalúrgicos, como lo indica Iribarren (1958) para La Turquía y los informantes locales que han participado en el despojo de estos sitios. Las fechas obtenidas en estos sitios son post-500 d.C. y traspasan el año 1.000 d.C. (Tabla 1). La datación de un sitio habitacional cercano a estos cementerios entrega fechas afines, siendo un contexto con mayor cantidad de fragmentería en comparación a aquellos pre500 d.C. y cerámica negra pulida similar a la de los contextos funerarios (Tabla 1).

De estos cementerios proviene la mayor cantidad de cerámica Molle depositada en colecciones de museos. De 211 vasijas analizadas procedentes de 39 sitios de Elqui-Limarí, al menos $97(45,9 \%)$ provienen de siete cementerios de este tipo. Son estos contextos los que muestran las cerámicas más elaboradas en términos visuales. Se reconocen técnicas ahumadas, incisas, grabadas, modeladas y pintadas. Destaca el registro de todos los patrones decorativos reconocidos para lo Molle (Pérez 2014). Tienen también los contextos materiales más complejos con presencia de metalurgia (oro y plata). También proviene de acá la mayor parte de las piezas asociadas al tipo Molle bicromo (Figura 8c), caracterizado por sus decoraciones escaleradas, y que en zonas aledañas se encuentra en asentamientos datados entre 800 a 1.200 d.C. (Troncoso et al. 2012), en coherencia con lo planteado por Iribarren (1958).

Los petroglifos de surco profundo, entre los que se encuentran las llamadas cabezas tiaras, se asociarían a este segmento post-500 d.C., pues algunos de sus diseños y patrón de simetría son similares a los de la cerámica Molle bicroma. La superposición de estos grabados sobre las pinturas avalan su carácter más tardío (Troncoso et al. 2008). A su vez, las cabezas tiaras inauguran la tradición de representar cabezas en el arte rupestre local, la que posteriormente será ampliada por los Diaguitas por medio de las máscaras. Sin embargo, mientras las cabezas tiaras enfatizan métricamente los tocados 

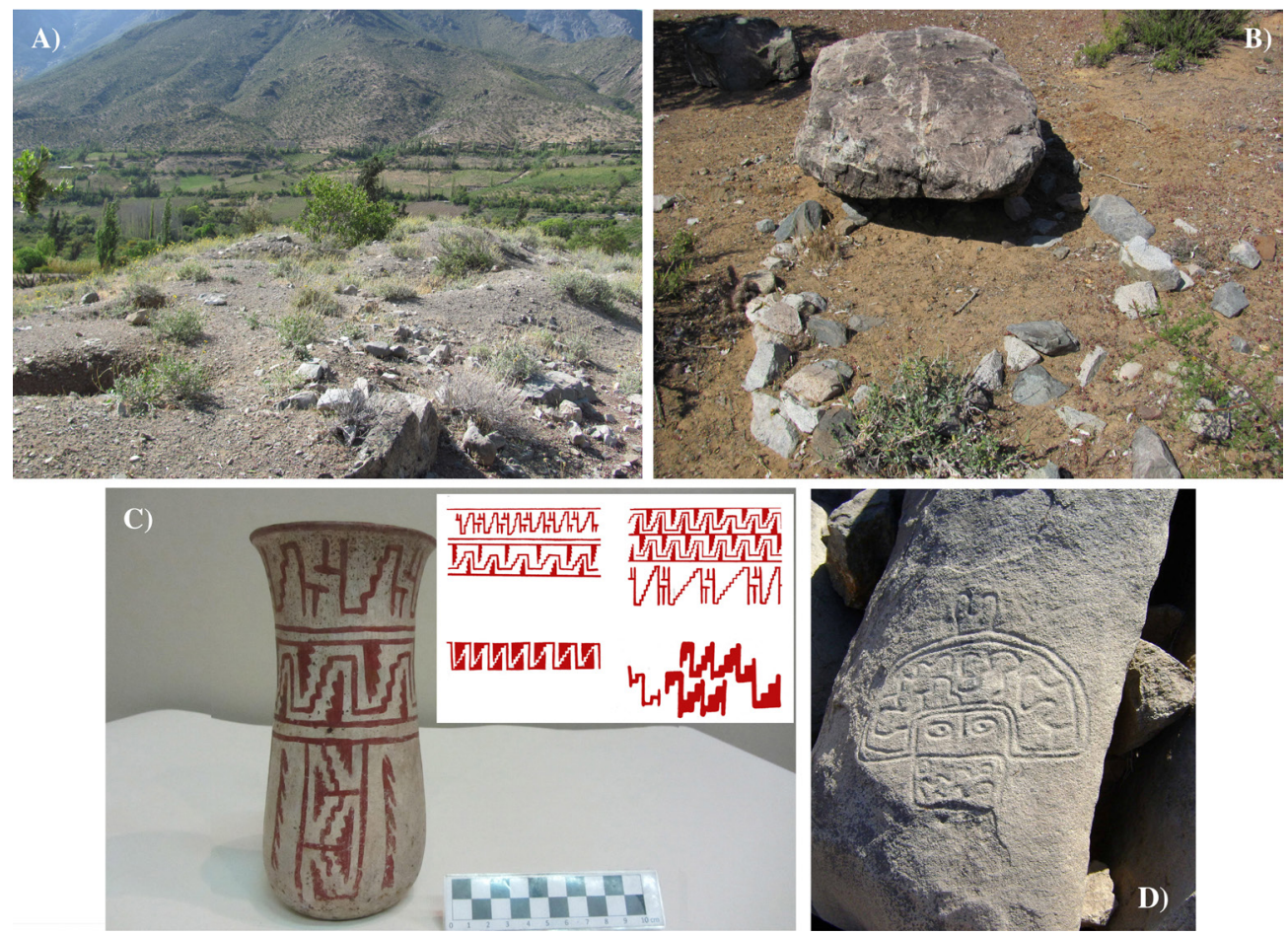

Figura 8. Contextos alfareros post-500 d.C., cementerio de ruedo de piedras de La Turquía: (a) vista del cementerio excavado y paisaje circundante, (b) posible tumba en ruedo; (c) cerámica bicroma y diseños escalerados, (d) cabeza tiara. Post-500 AD ceramic contexts, La Turquia stone ring cemetery: (a) View of the excavated cemetery and its surroundings, (b) probable ring grave, (c) bichrome and stepped designs ceramics, (d) head tiara.
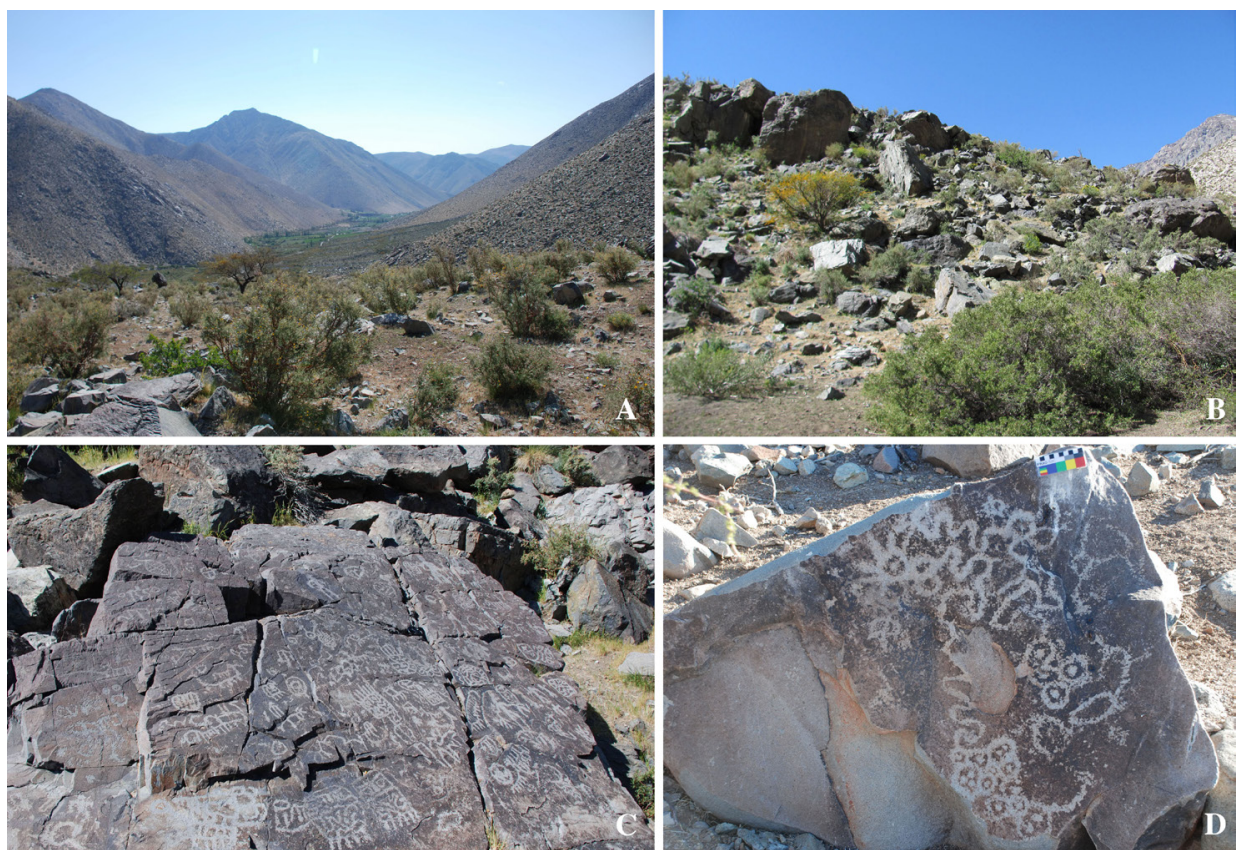

Figura 9. Arte rupestre Diaguita: (a y b) emplazamiento de los sitios, (c) bloque grabado cuesta Pabellón, (d) bloque grabado Hacienda Chacay.

Diaguita rock art: ( $a$ and b) location of sites, (c) Cuesta Pabellón carved block, (d) Hacienda Chacay carved block. 
cefálicos por sobre los rostros, las máscaras hacen lo inverso (Figura 8d y 9c).

El cambio de pinturas a grabados de surco profundo implica una modificación en la cadena operativa del arte rupestre. Mientras la de las pinturas supera la escala del sitio debido a la necesidad de adquisición de pigmentos, la de los grabados de surco profundo se centra en el sitio, pues su producción se realiza con instrumentos líticos expeditivos elaborados sobre materias primas locales (Vergara y Troncoso 2015). Su lógica descansa en una continua práctica de grabado y raspado que profundizan el surco, constituyendo una estrategia tecnológica de tipo intensiva centrada en el remarcado de los petroglifos en diferentes ocasiones (Vergara y Troncoso 2015). Estas modificaciones dan cuenta de un cambio en sus procedimientos técnicos, cadenas operativas y discursos visuales, en coherencia con las transformaciones que se dan post-500 d.C.

Estos datos indican que es en la segunda mitad del primer milenio donde se produce una importante transformación de las comunidades prehispánicas de la región. Estas implican una mayor recurrencia de la alfarería, incorporación y transformación de los lenguajes visuales, destacando la aparición de lo humano en el arte rupestre y la aparición del tipo Molle bicromo, así como la conformación de grandes cementerios que denotan trabajo colectivo y una intención de monumentalizar a los ancestros en el paisaje. Estos cambios sugieren la construcción de nuevas narrativas que se despliegan en el paisaje y la conformación de nuevos principios simbólicos que organizan las prácticas materiales. A pesar de los datos preliminares que tenemos, la mayor presencia de alfarería y tamaño de sitios sugeriría que nos encontramos ante grupos con una menor movilidad y en una etapa terminal de un proceso de sedentarización. Sin embargo, este cambio pareciera no ser homogéneo en todos los espacios, pues sitios como Rocas de Francisca, San Pedro Viejo o alero Roca Fértil tienen fechas tardías y mantienen características de los contextos pre-500 d.C. (Tabla 1).

Si bien se requieren aún más datos, lo cierto es que la información disponible de momento indica que, a diferencia de lo tradicionalmente planteado, la conformación de contextos más propios a lo Molle y la constitución de comunidades con un modo de vida que no replica las dinámicas del Arcaico Tardío se daría en el transecto 500-1.000 d.C.

\section{Variabilidad regional y el devenir de comunidades agrarias}

Entre los años 1.000-1.200 d.C. se observa la aparición de nuevos contextos asociados con la cultura Diaguita. El patrón de asentamiento se centra en el uso intensivo de las terrazas fluviales y la desocupación de quebradas interiores y conos de deyección. Evidencias claras de sitios del Complejo Las Ánimas no se han reconocido, remitiendo únicamente a fragmentos cerámicos superficiales en el sitio P-23 (Figura 7e) y los contextos de Puerto Aldea (Montané y Niemeyer 1960), todos ellos ubicados en la parte baja de la CHRL. Este hecho es coherente con lo discreto de estas ocupaciones en la cuarta región, pareciendo restringirse más bien a espacios costeros (Troncoso y Pavlovic 2013).

Los asentamientos Diaguita son recurrentes. La frecuencia de los sitios decrece, pero son más extensos en relación con tiempos previos. Muestran ocupaciones más consolidadas con abundante fragmentería cerámica proveniente de piezas de tamaños mediano a grande, una industria lítica basada en el uso de materias primas de disponibilidad inmediata de baja calidad y con predominio de categorías informales de rápida elaboración y fácil descarte, a excepción de las puntas de proyectil que se elaboran sobre lascas de sección delgada y en sílice (Figura 4h-i). Es un patrón de asentamiento disperso que concentra ocupaciones en algunos sectores del valle y que se ha definido para otras zonas como nucleado-disperso (Troncoso 1999). Coexisten con estos sitios amplios cementerios segregados de los espacios habitacionales (Iribarren 1970; Montané y Niemeyer 1960).

Como ocurre en otras áreas (Troncoso 1999), estos sitios han sido interpretados como unidades residenciales de comunidades sedentarias, coincidiendo su patrón de asentamiento con el de las actuales comunidades campesinas de la zona. Los espacios poco aptos para labores agrícolas, como áreas cordilleranas o terrazas fluviales bajas que pueden ser arrasadas por crecidas de ríos, no son ocupados. La consolidación del proceso de sedentarización y constitución de comunidades agrarias en esta región, por tanto, cristalizaría con la Cultura Diaguita. Estudios isotópicos sobre una pequeña muestra sugieren que es en este momento que se establece una dieta de corte más agrícola (Becker et al. 2015).

Los cementerios se emplazan en los fondos de valle en espacios próximos a zonas habitacionales. 
Esta posición no les entrega las condiciones de visibilidad que tienen los cementerios de ruedos de piedra. La reiterada ocupación de los cementerios Diaguita y la gran cantidad de enterratorios que ellos presentan (Cornely 1956) sugieren espacios de agregación para la reproducción social de estas comunidades.

A las propuestas de integración a amplia escala para estas comunidades (Ampuero e Hidalgo 1975), González $(2004,2010)$ ha sugerido un nivel de variabilidad intervalle al comparar los diseños decorativos de Elqui y Choapa. En Limarí esta variabilidad se observa también a nivel intravalle, pues mientras en la cuenca inferior y en Rapel predomina la clásica alfarería Diaguita en sus tipos Diaguita Policromo (Pavlovic et al. 2006) (Figura 7h-i), en Hurtado coexisten con cerámica similar al denominado tipo Ánimas con Banda Perimetral en Zig-Zag (Guajardo 2001), siendo este último el predominante y extendiéndose hasta el período Tardío. Este tipo tiene una decoración de trazos inscritos rojo, blanco y negro con hierro oligisto (Figura 7f-g). Reafirma su filiación Diaguita el haber sido encontrado asociado estratigráficamente con cerámica Diaguita tanto en Limarí, la costa del Elqui (Rodríguez 1973) y sitios del curso superior del río Illapel (Troncoso 1999), aunque con bajas frecuencias en los dos últimos espacios.

Los fechados de La Turquía muestran alguna contemporaneidad entre los cementerios con ruedos de piedras, cerámica tipo Molle y los asentamientos Diaguita (Tabla 1). La coexistencia temporal de ocupaciones Diaguita con comunidades con cultura material de tradición PAT ha sido reconocida en otros espacios del Semiárido (Pavlovic 2004; Troncoso et al. 2012), pero a la fecha desconocemos cuáles son las dinámicas de relación entre ambos tipos de comunidades. En Limarí, las prospecciones han mostrado que estos cementerios y sus sitios habitacionales asociados no coexisten con asentamientos Diaguita importantes, lo que replicaría la situación de Choapa, donde ambos tipos de contextos se segregan a nivel intra e intervalle.

Las comunidades Diaguita modifican las prácticas de producción de arte rupestre en relación con tiempos previos. Por un lado se produce un cambio tecnológico, ya que el surco profundo es reemplazado por el surco superficial en los grabados. Esto indica que la manufactura rupestre ya no se orienta al remarcado de los surcos, sino que es de carácter más extensiva centrada en la intervención de múltiples rocas y la creación de una gran cantidad de diseños a lo largo del espacio, pero de poca profundidad (Figura 9) (Vergara y Troncoso 2015).

Por otro, esta práctica se incrementa y segrega de los espacios habitacionales (Figura 9). Por su emplazamiento reconocemos dos tipos de sitios: (i) aquellos ubicados en los valles ocupados por las comunidades Diaguita y (ii) aquellos dispuestos en espacios cordilleranos transitados pero no habitados por estas comunidades.

Los primeros corresponden a sitios de 1 a 100 bloques grabados. Se ubican en los bordes de los valles, específicamente en quebradas o laderas de cerros asociados con rutas de movimiento que conectan con valles vecinos. Aunque segregados de los asentamientos habitacionales, estos sitios son accesibles en las prácticas diarias de las comunidades debido a su escasa distancia de los asentamientos habitacionales (menos de $5 \mathrm{~km}$ ). Son, por tanto, un discurso público que se materializa en los espacios que delimitan las zonas de ocupación Diaguita. Su emplazamiento permite el flujo de información y significados entre sujetos que circulan por tales espacios, independientemente de su copresencia, actuando como un recurso para la construcción de estas comunidades que por su patrón de asentamiento tienen bajos niveles de interacción cara a cara (Troncoso et al. 2014).

Los sitios conformados por más de 10 bloques presentan una organización lineal en la distribución de los soportes y el predominio de un rango de orientación específica. Este patrón sugiere que la observación y manufactura de grabados se ajusta a un circuito de circulación específico asociado a un movimiento de salida desde los valles. A ello se suma que su emplazamiento coincide con rutas naturales de tránsito que son utilizadas hasta hoy por las poblaciones locales. El flujo de información entre los diferentes integrantes de las comunidades se daría, por tanto, en un contexto de dinámicas de movilidad interregional (Troncoso y Vergara 2013; Troncoso et al. 2014).

Regionalmente se observa una variabilidad en las conductas manufacturadoras, pues el valle de Hurtado es donde más intensamente se da esta práctica, mientras que Rapel expresa la situación contraria (Tabla 3), reafirmando la variabilidad intrarregional reconocida en la alfarería.

Un segundo conjunto de sitios se ubica en zonas cordilleranas, alejados de todo espacio de ocupación Diaguita, y caracterizados por una 
Tabla 3. Registro de petroglifos de surco superficial por sector. Database of shallow groove petroglyphs per sector.

\begin{tabular}{|c|c|c|c|c|}
\hline & Limarí & Rapel & Hurtado & Internodos cordilleranos \\
\hline Sitios de arte rupestre & 25 & 12 & 51 & 2 \\
\hline Bloques de arte rupestre & 209 & 49 & 377 & 735 \\
\hline Densidad sitios por $\mathrm{km}^{2}$ & 0,46 & 0,46 & 1,45 & No calculable (zona no prospectada) \\
\hline Densidad bloques por $\mathrm{km}^{2}$ & 3,87 & 1,88 & 10,7 & No calculable (zona no prospectada) \\
\hline
\end{tabular}

alta intensidad de manufactura de arte rupestre. Hemos reconocido dos sitios de este tipo, hacienda Chacay (275 bloques) y La Tranca del Diablo (460 bloques). Estos mantienen el mismo patrón de organización espacial y se emplazan en puntos sensibles del paisaje donde se cruzan varias rutas de movilidad interregional. La mayor intensidad de producción en estos espacios internodales daría cuenta de una mayor relevancia de esta práctica para estos lugares, relacionándose con algún tipo de ritualidad del movimiento, pero también como recursos de reafirmación de la afiliación grupal al plasmar y compartir un lenguaje visual en estos espacios alejados.

La incorporación al Tawantinsuyu de la CHRL está evidenciada por diferentes sitios reconocidos en la literatura, destacando el cementerio Estadio Fiscal de Ovalle (Biskupovic 1999; Cantarutti 2002), Huana (Niemeyer 1969) y el trazado del QhapaqÑam asociado a instalaciones arquitectónicas que se emplazan en el valle de Hurtado dentro de una ruta que cruza hacia la vertiente oriental de los Andes (Stehberg 1995). Nuestras prospecciones no han registrado nuevas instalaciones asociadas al Tawantinsuyu, ni nuevos trayectos del QhapaqÑam. Tampoco se han reconocido claros indicadores de sitios o actividades minero-metalúrgicos, recurso que habría sido el detonador de la ocupación de este territorio según Llagostera (1976). Pero hemos reconocido ocupaciones de las comunidades locales en tiempos incaicos, interviniéndose los sitios de P-24 (sector inferior) y Dina Cortés (Hurtado). Estos presentan un patrón de asentamiento que continúa ocupaciones previas con contextos materiales donde junto al mencionado tipo Ánimas se reconoce una mayor cantidad de fragmentería de los tipos Diaguita Policromo, pero sin que se observe una fuerte intromisión de nuevos tipos alfareros (Figura 7j). Los pocos contextos excavados no muestran la presencia de alfarería con formas y/o diseños del Noroeste Argentino como sí ocurre en el cementerio Estadio Fiscal de Ovalle (Cantarutti y Mera 2003). Los registros zooarqueológicos de contextos Diaguita preincaicos e incaicos continúan mostrando el aprovechamiento de camélidos de gran tamaño, correspondientes posiblemente a guanacos (Lama guanicoe).

Mientras estos sitios muestran una reocupación de época preinca a incaica los asentamientos con arquitectura se segregan de tales espacios. Las instalaciones incaicas no reocupan sitios previos, pero se emplazan próximos a los lugares ocupados por las poblaciones locales y con buenas condiciones de visibilización de tales asentamientos (Figura 10). El camino incaico remite a un patrón similar, articulando las instalaciones incaicas, pero excluyendo los asentamientos locales. El valle de Hurtado sería un espacio más ampliamente intervenido por el Tawantinsuyu, pues como ya lo adelantó Stehberg (1995), es el lugar donde se observa una mayor inversión de mano de obra en términos de instalaciones.

La producción de arte rupestre continúa y mantiene los mismos patrones espaciales previos. Los sitios son reocupados, instalándose los nuevos grabados en nuevas rocas y en soportes previamente intervenidos, pero sin disturbar las composiciones previas, lo que se evidencia en una baja cantidad de superposiciones, y en el mantenimiento de las ordenaciones y estructuraciones internas de los sitios. Los procedimientos tecnológicos se mantienen, pero se incluye una nueva técnica: el grabado areal que le entrega mayor visibilidad a los diseños. Se complejizan los patrones de simetría con el ingreso de la rotación y la doble reflexión especular, documentados también en la alfarería. Se incorporan diseños propios al Tawantinsuyu como grecas incaicas, cuadrados de lados curvos, cruces inscritas y camélidos esquemáticos rígidos como los reconocidos para otras provincias (Figura 11). Diseños locales relevantes como las máscaras se complejizan también con la incorporación de 


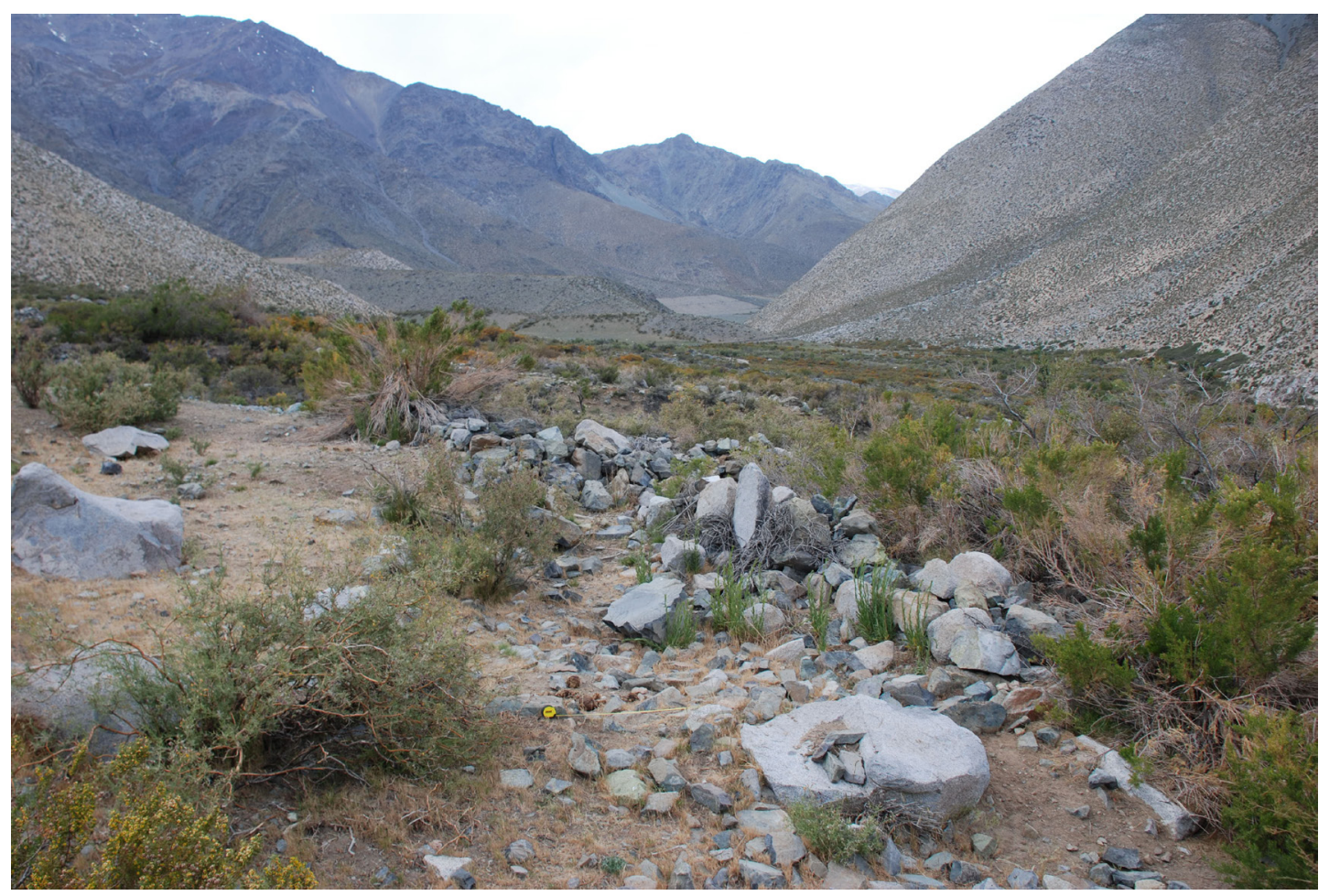

Figura 10. Control visual del valle de Hurtado desde la instalación incaica de Chacaicitio (en primer plano muros derruidos). Visual control of the Hurtado valley from the Chaicaicitio Inca facility (at the forefront collapsed walls).

patrones de simetría como los descritos previamente, o la inclusión de la greca incaica en su sector interior. Finalmente, aunque en baja cantidad, ingresan diseños propios al Noroeste Argentino, específicamente, escutiformes Santamarianos, los que se representan aisladamente o en asociación con camélidos y/o escenas de pastoreo (Figura 11a-b); se ubican exclusivamente en sitios del interior, tal como sucede en otros espacios del Norte Semiárido (Troncoso 2011). No obstante, la recurrencia del arte rupestre en la zona, estos sitios no se asocian al trazado del Qhapaq Nam, ni a las instalaciones incaicas.

La presencia de escutiformes Santamarianos da cuenta del prestigio que adquiere la iconografía asociada a estos personajes en diferentes provincias del Tawantinsuyu (Nielsen 2007; Tarrago et al. 1997), que permea diferentes espacios cordilleranos (Troncoso 2011) y que concuerda con el registro cerámico recuperado del Estadio de Ovalle (Cantarutti y Mera 2003). Ellos también quiebran la tradición local de representaciones antropomorfas más orientadas a la producción de sujetos sin volumen, generando un área en el cuerpo que posibilita incluir decoraciones a manera de textiles (Montt 2005), marcando una diferenciación en las formas en que las comunidades locales representan los sujetos y que es coherente con los procesos de diferenciación social que impone el Tawantinsuyu en sus provincias.

La incorporación de elementos incaicos da cuenta de procesos de asimilación de elementos visuales propios al Tawantinsuyu y del Noroeste Argentino, los que se fusionan e integran dentro de las estructuras espaciales de los asentamientos previos y con los paneles antes grabados. Sin embargo, ellos son excluidos de la estructura de organización espacial Incaica en la zona. De esta manera, un recurso material tradicional para la construcción de las comunidades Diaguita se excluye del paisaje material que crea el Tawantinsuyu, quedando como discursos visuales que la arquitectura del espacio promueve exclusivamente para los locales.

Las características de los contextos del Estadio Ovalle sumado a la incorporación de estos referentes propios al Noroeste Argentino en el arte rupestre mantienen la hipótesis de una anexión de este espacio desde la vertiente oriental de los Andes con una importante agencia de poblaciones trasandinas. El 

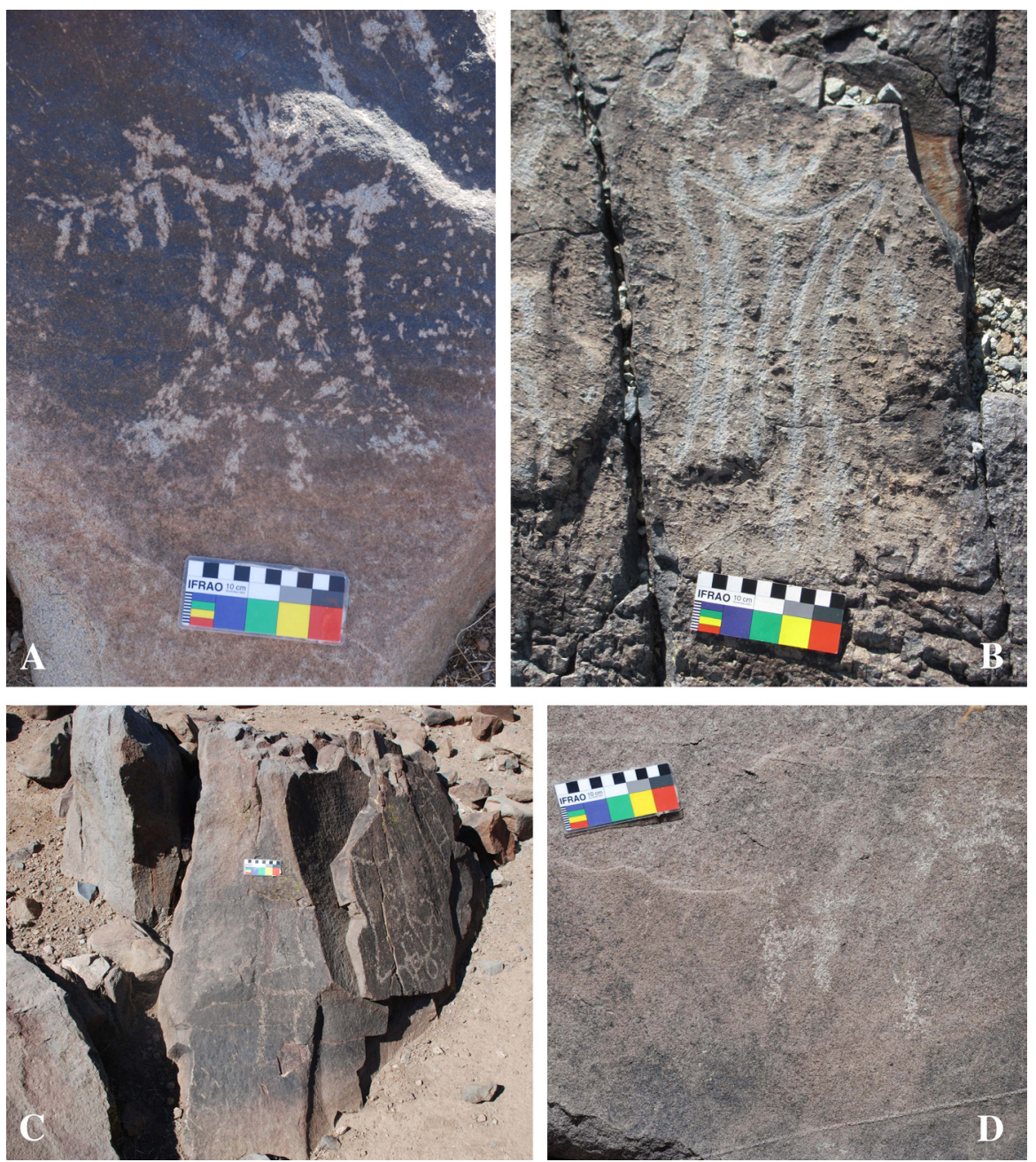

Figura 11. Arte rupestre de época Diaguita Incaica: (a y b) Escutiformes Santamarianos, sitios hacienda Chacay y cuesta Pabellón, (c) Cuadrado de lados curvos, (d) camélido esquemático rígido, sitio hacienda Chacay. Inca Diaguita period rock art: ( $a$ and b) Santamarian shield-like motifs (Hacienda Chacay and Cuesta Pabellón), (c) square with concave sides, (d) rigid schematic camelid (Hacienda Chacay).

escaso registro de alfarería alóctona a la región en contextos habitacionales no negaría tal hipótesis, sino que daría cuenta de una situación recurrente en los espacios domésticos de las provincias anexadas. Una de las cabeceras de este proceso habría sido el Complejo Arquitectónico de Huana, el que por la alta cantidad de alfarería decorada $(50 \%)$, aríbalos, platos planos, keros e inclusive alfarería cuzqueña (Niemeyer 1969-70), daría cuenta de su funcionamiento como centro administrativoceremonial en el que se desplegaron actividades político-rituales, especialmente comensalismo político, como lo sugiere su vajilla (Bray 2003; Niemeyer 1969-70).

\section{Conclusiones}

El estudio espacial y contextual de la evidencia arqueológica reconocida en la cuenca hidrográfica del río Limarí nos ha llevado a proponer un modelo asociado a procesos y desarrollos históricos que muestran divergencias con las propuestas tradicionalmente manejadas para la zona. A su vez, estos procesos presentan particularidades propios a esta zona y que marcan diferencias con las situaciones conocidas en el extremo septentrional (CopiapóHuasco) y meridional (Combarbalá-Choapa) del Norte Semiárido (Méndez y Jackson 2004; Troncoso y Pavlovic 2013). Si bien para analizar y ordenar la 
evidencia hemos utilizado las categorías temporales tradicionalmente definidas para la zona (p.ej., Alfarero Temprano, Intermedio Tardío), estas en ocasiones oscurecen procesos históricos de cambios como los ocurridos en el primer milenio de nuestra era, o la coexistencia de grupos con diferentes tradiciones materiales entre el 1.000 y 1.500 d.C., como lo evidencia el sitio La Turquía.

Los resultados que hemos obtenido nos permiten, de momento, ordenar la información en distintos momentos temporales que deben ser profundizados y reevaluados a futuro con nuevas y más profundas investigaciones.

Un primer segmento corresponde a las primeras ocupaciones de la zona hasta el Holoceno Medio, del cual manejamos poca información debido a su baja visibilidad en el registro local. Mientras los asentamientos del Holoceno Temprano muestran una ocupación de la costa y valles cordilleranos según lo planteado por Jackson y Méndez (2005), queda aún por clarificar la dinámica de uso del espacio de los grupos asociados a San Pedro Viejo, y las posibles interacciones entre estos grupos y Huentelauquén (Jackson 1997) a la luz de los hallazgos de puntas pedunculadas en San Pedro Viejo (Ale 2014). Las ocupaciones del Holoceno Medio, aunque de baja señal arqueológica, coinciden con las dinámicas extrarregionales definidas por Méndez et al. (2015), desplegando una forma de ocupación del espacio que en el interior será replicada e intensificada por los grupos cazadores recolectores del Holoceno Tardío.

Un segundo segmento abarcaría desde inicios del Holoceno Tardío hasta aproximadamente el año 500 d.C., momento en el que se establecen las primeras estrategias de monumentalización del paisaje en un contexto de una movilidad residencial por parte de las comunidades cazadoras recolectoras. Este segmento muestra transformaciones en su interior que se asocian a procesos de reducción de la movilidad, cambio en el patrón de asentamiento que lleva a una menor ocupación de la costa con la desarticulación de los grandes conchales-cementerios. Estos procesos marcarían diferencias entre el interior y la costa. La incorporación de la alfarería, en este contexto, si bien puede entenderse como un proceso de adopción de una nueva tecnología y materialidad, no articularía necesariamente con el ingreso de nuevas poblaciones, ni despliega grandes modificaciones socioeconómicas. Por el contrario, es posible pensar que esto se da dentro de un proceso de reducción de movilidad que despliegan las comunidades desde el Arcaico Tardío y que a inicios de la era cristiana lleva aparejada la adopción de la cerámica y la popularización de las piedras tacitas. Aunque se requieren más dataciones, los fechados más tempranos de la cerámica en los valles costeros podrían remitir a este proceso inicial a tal sector.

La situación antes mencionada no debería extrañar, pues en regiones vecinas como Chile central o el Centro Oeste argentino, la aparición de la alfarería no marca un quiebre radical en las dinámicas de las comunidades cazadoras recolectoras (p.ej., Gil et al. 2011; Sanhueza et al. 2003). De hecho, para Chile central una modificación substancial ocurre avanzado hacia el primer milenio con el Complejo Cultural Llolleo (Sanhueza et al. 2013). Para la zona meridional del Semiárido, los estudios en el valle del Choapa muestran una intensificación de las ocupaciones Alfareras Tempranas hacia el 700800 d.C. (Troncoso et al. 2012).

En nuestra región, es entre 500-1.000 d.C. que se observa una significativa transformación del registro de las primeras comunidades alfareras. Aunque es necesario caracterizar mejor este momento, lo cierto es que en ellas se incorporan nuevos principios visuales y prácticas socioespaciales que parecen ir junto con una movilidad muy reducida de estos grupos. Pareciera ser este tiempo un momento de transición hacia lo Diaguita, como lo propuso en su momento Iribarren (1958), sugiriendo una dinámica paulatina y heterogénea de transformación entre lo que se conoce como Molle y Diaguita. Esto sería coherente con la propuesta de un cambio asociado a la circulación y adopción de nuevos saberes y principios simbólicos por parte de las comunidades locales, las cuales las adaptan y adoptan dentro de la lógica de sus prácticas y en relación con sus trayectorias históricas específicas (Troncoso y Pavlovic 2013).

Un último segmento se corresponde al despliegue y desarrollo de las comunidades agrícolas de la región, las que si bien tienen sus antecedentes en las dinámicas reconocidas entre 500-1.000 d.C., cristalizan con el desarrollo de la Cultura Diaguita y su posterior incorporación dentro del Tawantinsuyu. En este transecto temporal coexistirían grupos con distintas tradiciones materiales y que serían fruto de procesos diferenciales de transformación histórica, como lo sugiere la existencia de contextos con cultura material tipo Molle post-1.000 d.C. 
La práctica de producir arte rupestre se desplegaría a lo largo de algunos de estos bloques, articulando con procesos de reproducción social que son divergentes entre cazadores recolectores y sociedades agrícolas. A diferencia de lo tradicionalmente planteado, o lo que ocurre en otros contextos, su manufactura sería más recurrente en tiempos Tardíos que en contextos de cazadores recolectores, lo que se asociaría a la relevancia que adquiere esta materialidad y práctica en la integración de comunidades sedentarias con escasa interacción cara a cara.

Lo anterior da cuenta de procesos complejos de transformaciones y continuidades sociales, materiales y espaciales en el registro, intersectándose en un mismo momento histórico prácticas, materialidades y paisajes propios de distintas comunidades sin que de momento entendamos cómo ellas interactúan.

Agradecimientos: Al Museo del Limarí, Museo Arqueológico La Serena, Museo Nacional de Historia Natural, Museo de Artes Visuales, Centro Nacional de Conservación y Restauración, CONICYT que financió este trabajo mediante FONDECYT 1110125. A los compañeros de terreno, Lorena Sanhueza por sus comentarios a una versión preliminar de este manuscrito, Daniela Serani, Gabriela Alt, Guillermo Villar y a las comunidades de Hurtado y Rapel que nos han acogido de excelente manera. A los evaluadores externos por sus comentarios que permitieron mejorar nuestro trabajo. Las omisiones y errores son de nuestra exclusiva responsabilidad.

\section{Referencias Citadas}

Ale, A. 2014. Una formación económico social de cazadores recolectores en el Norte Semiárido de Chile: Una reevaluación del sitio San Pedro Viejo de Pichasca. La Zaranda de Ideas 10:133-153.

Ampuero, G. 1966. Pictografías y Petroglifos de la Provincia de Coquimbo: El Panul, Lagunillas y El Chacay. Notas del Museo Arqueológico de La Serena 9:1-14.

Ampuero, G. 1969. Cárcamo, un taller precerámico en la provincia de Coquimbo. Boletín del Museo Arqueológico de La Serena 13:52-57.

Ampuero, G. 1971. Nuevos resultados de la arqueología del Norte Chico. Actas del VI Congreso Nacional de Arqueología Chilena, pp. 311-338. Universidad de Chile, Santiago.

Ampuero, G. 2010. Prehistoria de la Región de Coquimbo. Impresora Andros, Santiago.

Ampuero, G. y J. Hidalgo 1975. Estructura y proceso en la prehistoria y protohistoria del Norte chico de Chile. Chungara 5:87-124.

Ampuero, G. y M. Rivera 1964. Excavaciones en la quebrada El Encanto, Departamento de Ovalle (informe preliminar). Actas del III Congreso Internacional de Arqueología Chilena, Arqueología de Chile central y áreas vecinas, pp. 207-218. Sociedad Chilena de Arqueología, Viña del Mar.

Ampuero, G. y M. Rivera 1969. Excavaciones en quebrada El Encanto, nuevas evidencias. Actas del V Congreso Nacional de Arqueología Chilena, pp. 185-206. Museo Arqueológico La Serena, La Serena.

Ampuero, G. y M. Rivera 1971a. Las manifestaciones rupestres y arqueológicas del valle del Encanto. Boletín del Museo Arqueológico de La Serena 14:71-103.

Ampuero, G. y M. Rivera 1971b. Secuencia arqueológica del alero rocoso de San Pedro Viejo de Pichasca. Boletín del Museo Arqueológico de La Serena 14:45-69.
Ampuero, G. y M. Rivera 1972/73. Síntesis interpretativa de la arqueología del Norte Chico. Actas del VI Congreso de Arqueología Chilena, pp. 339-343.

Becker, C., M. Alfonso, N. Misarti, A. Troncoso y P. Larach 2015. Isótopos estables y dieta en poblaciones prehispánicas del norte semiárido $\left(30^{\circ}-32^{\circ}\right.$ Lat. S): Una primera aproximación desde el Arcaico Tardío hasta el período Incaico. Boletín del Museo Nacional de Historia Natural 64:107-119.

Biskupovic, M. 1999. Excavación arqueológica en la planta pisco control de Ovalle, IV región, Chile. El Limarí y sus Valles 1:7-27.

Billman, B. y G. Feinman 1999. Settlement Pattern Studies in the Americas: Fifty Years since Viru. Smithsonian Institution Press, Washington, DC.

Bray, T. 2003. To dine splendidly: imperial pottery, commensal politics and the Inca State. En The Archaeology and Politics of Food and Feasting in Early States and Empires, editado por T. Bray, pp. 93-142. Kluwer Academics, New York.

Cantarutti, G. 2002. Estadio Fiscal de Ovalle, Redescubrimiento de un Sitio Diaguita-Inca en el Valle de Limarí. Memoria para optar el título de Arqueólogo. Departamento de Antropología, Universidad de Chile, Santiago.

Cantarutti G. y R. Mera 2003. Alfarería de la fase Inca en el valle del Limarí: evidencias de influencia Yavi o Chicha en jarros antropomorfos. Actas del $4^{\circ}$ Congreso Chileno de Antropología Tomo II, pp. 1383-1391, Santiago.

Cantarutti G. y R. Mera 2004. Estadio Fiscal de Ovalle: redescubrimiento de un sitio diaguita-inka en el valle del Limarí. Chungara Revista de Antropología Chilena Volumen Especial pp. 833-845.

Cantarutti, G. y C. Solervicens 2005. Cultura Diaguita preincaica en el valle del Limarí: una aproximación a partir del estudio de colecciones cerámicas. Actas del XVI Congreso Nacional de Arqueología Chilena, pp. 147-156. Museo de Concepción, Tomé. 
Castelleti, J., M. Biskupovic, M. Campano, A. Guajardo, A. Delgado, P. Peralta, S. Alfaro, L. Quiroz, P. Acuña, V. Abarca, C. Castillo, J. Lillo y L. Olguín 2012. Adaptaciones costeras durante el Arcaico Tardío del semiárido: nuevos aportes con el estudio del sitio Museo del Desierto. Actas del XVIII Congreso Nacional de Arqueología Chilena, pp. 261-268. Sociedad Chilena de Arqueología, Valparaíso.

Castillo, G. 1985. Revisión del arte rupestre Molle. En Estudios en Arte Rupestre, editado por C. Aldunate, J. Berenguer y V. Castro, pp. 173-194. Museo Chileno de Arte Precolombino, Santiago.

Chang, K. 1983. Nuevas Perspectivas en Arqueología. Alianza Editorial, Madrid.

Cornely, F. 1956.Cultura Diaguita Chilena y Cultura El Molle. Editorial del Pacífico, Santiago.

Criado, F. 2012. Arqueológicas: La Razón Perdida. Bellaterra Arqueología, Barcelona.

Escudero, A. 2012. La Fundición 1: Campamento Interior del Complejo Cultural Huentelauquén. Memoria para optar al título de Arqueóloga. Departamento de Antropología, Universidad de Chile, Santiago.

Gamble, C. 1982. Interaction and Alliance in Palaeolithic Society. MAN, New Series 17:92-107.

Gil, A., G. Neme y R. Tykot 2011. Stable isotope and human diet in central western Argentina. Journal of Archaeological Science 38:1395-1404.

González, P. 2004. Patrones decorativos y espacio: el arte visual diaguita y su distribución en la cuenca del río Illapel. Chungara Revista de Antropología Chilena Volumen Especial pp. 767-781.

González, P. 2010. Nuevos resultados en la sistematización de los patrones decorativos Diaguita-Inca: Variabilidad, simbolismo, oposiciones intervalle y contextualización. Actas del XVII Congreso Nacional de Arqueología Chilena, Tomo I, pp. 241252. Ediciones Kultrún, Valdivia.

Guajardo, A. 2011. El Complejo Cultural Las Ánimas y sus Vínculos con la Cultura Diaguita en la Región de Coquimbo: Una Aproximación desde la Alfarería. Memoria para optar al título de Arqueólogo. Departamento de Antropología, Universidad de Chile. Santiago.

Hogg, A.G., Q. Hua, P.G. Blackwell, M. Niu, C.E. Buck, T.P. Guilderson, T.J. Heaton, J. Palmer, P. Reimer, R.W. Reimer, C. Turney y S.H.H. Zimmerman 2013. SHCAL13 Southern Hemispere Calibration, 0-50,000 years cal BP. Radiocarbon 55:1-15.

Ingold, T. 1993. The temporality of landscape. World Archaeology 25:152-174.

Iribarren, J. 1949. Paradero indígena del Estero Las Peñas, Ovalle-Provincia de Coquimbo. Publicaciones del Museo Arqueológico de La Serena, Boletín 4:14-16.

Iribarren, J. 1953. Revisión de los petroglifos del valle de río Hurtado. Revista Universitaria XXXVIII:189-193.

Iribarren, J. 1958. Nuevos hallazgos arqueológicos en el cementerio indígena de La Turquía-Hurtado. Arqueología Chilena 4:13-40.

Iribarren, J. 1970. Arqueología y Antecedentes Históricos del Valle del Río Hurtado. Ediciones del Museo Arqueológico de La Serena, La Serena.
Iribarren, J. 1973. Pictografías en las provincias de Atacama y Coquimbo, Chile. Boletín del Museo Arqueológico de La Serena 15:115-132.

Iribarren, J. 1975. Arqueología en la Hoya Hidrográfica del Río Limarí, IV Región. Museo Arqueológico La Serena, La Serena.

Jackson, D. 1997. Coexistencia e interacción de comunidades cazadores-recolectores del Arcaico Temprano en el semiárido de Chile. Valles Revista de Estudios Regionales 3:13-36.

Jackson, D. 2002. Cazadores y Recolectores del Holoceno Medio del Norte Semiárido de Chile. Tesis para optar al grado de Magíster en Arqueología. Departamento de Antropología, Universidad de Chile. Santiago.

Jackson D. y C. Méndez 2005. Primeras ocupaciones humanas en la costa del semiárido de Chile: patrones de asentamiento y subsistencia. Actas del XVI Congreso Nacional de Arqueología Chilena, pp. 493-502. Ediciones Escaparate, Concepción.

Latcham, R. 1928. La prehistoria Chilena. Soc. Imprenta y Litografía Universo, Santiago.

Latcham, R. 1937. Arqueología de los indios Diaguitas. Boletín del Museo Nacional de Historia Natural XVI:17-35.

Llagostera, A. 1976. Hipótesis sobre la expansión incaica en la vertiente occidental de los Andes Meridionales. En Homenaje al Dr. G. Le Paige, pp. 203-218. Universidad del Norte, Antofagasta.

Maldonado, A. y C. Villagrán 2002. Paleoenvironmental changes in the semiarid coast of Chile $\left(\sim 32^{\circ} \mathrm{S}\right)$ during the last $6200 \mathrm{cal}$ years inferred from a swamp-forest pollen record. Quaternary Research 58:130-138.

Maldonado, A. y C. Villagrán 2006. Variability of the Northern limit of the Southern Westerlies over the last $9900 \mathrm{cal}$ yr BP from a swamp forest pollen record along the semiarid coast of Chile (3205'S). Quaternary Research 66:246-258.

McDonald, J. y P. Veth 2006. Rock art and social identity: a comparison of Holocene graphic systems in arid and fertile environments. En Archaeology of Oceania: Australia and the Pacific Islands, editado por I. Lilley, pp. 96-115, Wiley-Blackwell.

Méndez, C., A. Gil, G. Neme, A. Nuevo, V. Cortegoso, C. Huidobro, V. Durán y A. Maldonado 2015. Mid Holocene radiocarbon ages in the Subtropical Andes $\left(29^{\circ}-35^{\circ} \mathrm{S}\right)$, climatic change and implications for human space organization. Quaternary International 356:15-26.

Méndez, C. y D. Jackson 2004. Ocupaciones humanas del Holoceno Tardío en Los Vilos (IV región): origen y características conductuales de la población local de cazadores recolectores del litoral. Chungara Revista de Antropología Chilena 36:279-293.

Méndez, C. y D. Jackson 2006. Causalidad o Concurrencia, relaciones entre cambios ambientales y sociales en los cazadores recolectores durante la transición entre el Holoceno Medio y Tardío (Costa del Semiárido de Chile). Chungara Revista de Antropología Chilena 38:173-184.

Méndez, C. y D. Jackson 2008. La ocupación prehispánica de Combarbalá: una propuesta sintética. Chungara Revista de Antropología Chilena 40:5-17.

Méndez, C., A. Troncoso, D. Pavlovic y D. Jackson 2009. Movilidad y uso del espacio entre cazadores recolectores 
tardíos en espacios cordilleranos del Norte Semiárido de Chile. Intersecciones en Antropología 10:313-326.

Montané, J. y H. Niemeyer 1960. Arqueología Diaguita en conchales de la costa. Boletín del Museo Arqueológico de La Serena 11:53-75.

Montt, I. 2005. Vestimenta en la Cultura Visual Tardía del Desierto de Atacama. Memoria inédita para optar al título de Arqueólogo. Departamento de Antropología, Universidad de Chile, Santiago.

Moya, F. 2015. Variabilidad Tecnológica de las Pinturas Rupestres de la Cuenca del Río Limarí. Memoria para optar al título de Arqueóloga. Departamento de Antropología, Universidad de Chile, Santiago.

Moya, F., F. Armstrong, M. Basile, G. Nash, A. Troncoso y F. Vergara 2014. On site and post site analysis of pictographs within the San Pedro Viejo de Pichasca rock shelter, Limari valley, North-central Chile. Proceedings of the University of Bristol Spelealogical Society 26:171-184.

Niemeyer, H. 1969. El yacimiento arqueológico de Huana. Boletín de Prehistoria de Chile 2-3:2-65.

Niemeyer, H. y D. Ballereau 2004. Arte rupestre del río Grande, cuenca del río Limarí, Norte Chico, Chile. Chungara Revista de Antropología Chilena 36:37-101.

Niemeyer, H., G. Castillo y M. Cervellino 1989. Los primeros ceramistas del Norte Chico: Complejo El Molle (0 a 800 d. C.). En Culturas de Chile, Prehistoria, editado por J. Hidalgo, V. Schiappacasse, H. Niemeyer, C. Aldunate e I. Solimano, pp. 227-263. Editorial Andrés Bello, Santiago.

Nielsen, A. 2007. Armas significantes: tramas culturales, guerra y cambio social en el sur andino prehispánico. Boletín del Museo Chileno de Arte Precolombino 12:9-41.

Pavlovic, D. 2004. Dejando atrás la tierra de nadie: asentamientos, contextos y movilidad de las comunidades alfareras tempranas del Choapa. Werken 5:39-46.

Pavlovic, D., A. Troncoso, C. Becker, J. Rodríguez y P. González 2006. Escobillado, cuarto estilo y grandes contenedores: el conjunto alfarero Diaguita durante el período Inca en la Provincia del Choapa. Actas del XVII Congreso Nacional de Arqueología Chilena, Tomo I, pp. 285-296. Kultrún Ediciones, Santiago.

Pérez, I. 2012. Reevaluando el Complejo Cultural El Molle en los valles de Elqui y Limarí: una aproximación a partir de sus conjuntos alfareros de vasijas completas. Actas del XIX Congreso Nacional de Arqueología Chilena. Arica. En prensa.

Pino, M. 2012. Algunas consideraciones en torno al problema de las piedras tacitas en el Valle El Encanto (Ovalle, Chile): una aproximación a su organización espacial. Actas del XVIII Congreso Nacional de Arqueología Chilena, pp. 297-308. Sociedad Chilena de Arqueología, Valparaíso.

Quevedo, S. 1998. Punta Teatinos: Biología de una Población Arcaica del Norte Semiárido Chileno. Ph.D. Tesis, Facultad de Filosofía y Letras, Universidad de Buenos Aires, Buenos Aires.

Rodríguez, A. 1973. Conchal cerámico en un sector urbano del puerto de Coquimbo. Boletín Museo Arqueológico La Serena 15:175-188.

Sanhueza, L., M. Vásquez y L. Cornejo 2003. Las sociedades alfareras tempranas de la cuenca de Santiago. Chungara Revista de Antropología Chilena 35:23-50.
Santander, B. y P. López 2012. Análisis de microhuellas de uso mediante microscopio electrónico de barrido (MEB) de artefactos óseos de un sitio Arcaico Tardío del valle de Mauro. Revista Chilena de Antropología 26:129-150.

Serani, D., G. Cantarutti, R. Seguel y F. Eisner 2004. Cultura Diaguita en San Julián: aportes a la prehistoria del valle del Limarí y del norte semiárido chileno. Fondo de apoyo a la investigación patrimonial 2003:36-42.

Schiappacasse, V. y H. Niemeyer 1964. Excavaciones de un conchal en el pueblo de Guanaqueros (Provincia de Coquimbo). Actas del 3er Congreso Chileno de Arqueología, pp. 235-262. Sociedad Chilena de Arqueología, Viña del Mar.

Schiappacasse, V. y H. Niemeyer 1965-1966. Excavaciones de conchales precerámicos en el litoral de Coquimbo, Chile (Quebrada Romeral y Punta Teatinos). Revista Universitaria L-LI (II):277-313.

Stehberg, R. 1995. Instalaciones Incaicas en el Norte y Centro Semiárido de Chile. Centro de Investigaciones Diego Barros Arana, DIBAM, Santiago.

Suárez, L., L. Cornejo, A. Deza y A. Román 1989. Primeros fechados absolutos para la Cultura Diaguita. Actas del XI Congreso Nacional de Arqueología Chilena, tomo III, pp. 49-56. Sociedad Chilena de Arqueología, Santiago.

Tarragó, M., L. González y J. Nastri 1997. Las interacciones prehispánicas a través del estilo: el caso de la iconografía santamariana. Estudios Atacameños 14:223-242.

Troncoso, A. 1999. La cultura Diaguita en el valle de Illapel, una perspectiva exploratoria. Chungara 30:125-142.

Troncoso, A. 2011. Personajes fuera de lugar: antropomorfos tardíos en el arte rupestre del Norte semiárido de Chile. Intersecciones en Antropología 12:221-230.

Troncoso, A., F. Armstrong, F. Vergara, P. Urzúa y P. Larach 2008. Arte rupestre en el valle El Encanto: Hacia una reevaluación del sitio-tipo del Estilo Limarí. Boletín del Museo Chileno de Arte Precolombino 13:9-36.

Troncoso, A., P. Larach, S. Alfaro, D. Pascual y D. Pavlovic 2012. Nuevos antecedentes para el período alfarero temprano en el valle del Choapa: El sitio Los Mellizos (Cuenca superior del río Illapel). Actas del XVIII Congreso Nacional de Arqueología Chilena, pp. 309-319. Sociedad Chilena de Arqueología, Santiago.

Troncoso, A. y D. Pavlovic 2013. Historias, saberes y prácticas: un ensayo sobre el desarrollo de las comunidades alfareras del norte semiárido de Chile. Revista Chilena de Antropología 27:101-140.

Troncoso, A., D. Pavlovic, C. Becker, P. González y J. Rodríguez 2004. Césped 3, asentamiento del período Diaguita-Incaico sin cerámica Diaguita Fase III en el curso superior del río Illapel, IV región, Chile. Chungara Revista de Antropología Chilena Volumen Especial, pp. 893-906.

Troncoso, A., M. Pino y C. Belmar 2015. Piedras Tacitas, Prácticas Socio-Espaciales, Comunidades y Paisaje en la cuenca hidrográfica del río Limarí. Manuscrito en posesión de los autores.

Troncoso, A., F. Vergara, P. González, P. Larach, M. Pino, F. Moya y R. Gutierrez 2014. Arte rupestre, prácticas socio-espaciales y la construcción de comunidades en el Norte Semiárido de Chile (Valle de Limarí). En Distribución Espacial en Sociedades no 
Aldeanas: del Registro a la Interpretación Social, editado por F. Falabella, L. Sanhueza, L. Cornejo e I. Correa, pp. 89-115. Monografías de la Sociedad Chilena de Arqueología 4, Santiago.

Troncoso, A. y F. Vergara 2013. History, landscape and social life: Rock art among hunter gatherers and farmers in Chile's Semi-Arid North. Time \& Mind: The Journal of Archaeology, Consciousness and Culture 6:105-112.

Vergara, F., L. Vargas, J. Hernández, M. Rebolledo, F. Fernández y P. Peralta 2012. Grupos cazadores recolectores con cerámica en el norte semiárido de Chile. Ponencia presentada en el XIX Congreso Nacional de Arqueología Chilena, Arica.

Vergara, F. y A. Troncoso 2015. Rock art, technique and technology: an exploratory study of hunter gatherer and agrarian communities in prehispanic Chile (500 to $1450 \mathrm{CE}$ ). Rock Art Research 32:31-45.
Villa, R. y C. Villagrán 1997. Historia vegetacional de bosques pantanosos de la costa de Chile central durante el Holoceno medio y tardío. Revista Chilena de Historia Natural 70:391-401.

Weisner, R. 1969. Un conchal precerámico en la bahía teniente y sus correlaciones con la cultura Huentelauquén. Actas del V Congreso Nacional de Arqueología Chilena, pp. 221-255. Museo Arqueológico de La Serena, La Serena.

Whallon, R. 2011. An introduction to information and its role in hunter-gatherer bands. En Information and Its Role in Hunter-Gatherer Bands, edited por R. Whallon, W. Lovis y R. Hitchcock, pp. 1-28. Cotsen Institute of Archaeology Press, Los Angeles.

Willey, G. y P. Phillips 1958. Method and Theory in American Archaeology. University of Chicago Press, Chicago. 